\title{
Agronomic and Physiological Traits, and Associated Quantitative Trait Loci (QTL) Affecting Yield Response in Wheat (Triticum aestivum L.): A Review
}

\author{
Nkhathutsheleni Maureen Tshikunde ${ }^{1,2}$, Jacob Mashilo ${ }^{1,2,3}$, Hussein Shimelis ${ }^{1,2 *}$ \\ and Alfred Odindo ${ }^{2}$

\begin{abstract}
${ }^{1}$ African Centre for Crop Improvement (ACCI), University of KwaZulu-Natal, Pietermaritzburg, South Africa, ${ }^{2}$ School of South Africa, ${ }^{3}$ Limpopo Department of Agriculture and Rural Development, Research Services, Towoomba Research
\end{abstract} \\ Agricultural, Earth and Environmental Sciences, Discipline of Crop Science, University of KwaZulu-Natal, Pietermaritzburg, \\ Station, Bela-Bela, South Africa
}

OPEN ACCESS

Edited by:

Soren K. Rasmussen, University of Copenhagen, Denmark

Reviewed by: Matthew Paul Reynolds, International Maize and Wheat Improvement Center (Mexico),

Mexico

Sivakumar Sukumaran, International Maize and Wheat Improvement Center (Mexico),

Mexico

*Correspondence: Hussein Shimelis

Shimelish@ukzn.ac.za

Specialty section: This article was submitted to Plant Breeding,

a section of the journal

Frontiers in Plant Science

Received: 10 May 2019 Accepted: 15 October 2019 Published: 05 November 2019

Citation:

Tshikunde NM, Mashilo J, Shimelis H and Odindo A (2019) Agronomic and Physiological Traits, and Associated Quantitative Trait Loci (QTL) Affecting Yield Response in Wheat (Triticum aestivum L.): A Review.

Front. Plant Sci. 10:1428 doi: 10.3389/fpls.2019.01428
Enhanced grain yield has been achieved in bread wheat (Triticum aestivum L.) through development and cultivation of superior genotypes incorporating yield-related agronomic and physiological traits derived from genetically diverse and complementary genetic pool. Despite significant breeding progress, yield levels in wheat have remained relatively low and stagnant under marginal growing environments. There is a need for genetic improvement of wheat using yield-promoting morpho-physiological attributes and desired genotypes under the target production environments to meet the demand for food and feed. This review presents breeding progress in wheat for yield gains using agronomic and physiological traits. Further, the paper discusses globally available wheat genetic resources to identify and select promising genotypes possessing useful agronomic and physiological traits to enhance water, nutrient-, and radiation-use efficiency to improve grain yield potential and tolerance to abiotic stresses (i.e. elevated $\mathrm{CO}_{2}$, high temperature, and drought stresses). Finally, the paper highlights quantitative trait loci (QTL) linked to agronomic and physiological traits to aid breeding of high-performing wheat genotypes.

Keywords: morphological traits, physiological traits, quantitative trait loci, yield gains, wheat

\section{INTRODUCTION}

Wheat (Triticum aestivum L., $2 \mathrm{n}=6 \mathrm{x}=42$ ) is the world's third important staple food crop after maize (Zea mays) and rice (Oryza sativa). It is the most widely grown crop globally (FAOSTAT, 2018). The crop is a vital source of proteins, carbohydrates, vitamins (e.g. B1, B2, B3 and E), and mineral elements (e.g. Se, $\mathrm{Mn}, \mathrm{P}$ and $\mathrm{Cu}$ ). Wheat is used for food, industrial raw material to prepare alcoholic beverages, starch and straws, and animal feed (Nhemachena and Kirsten, 2017).

Globally, 79\% of total wheat production comes from China, United States of America, Turkey, Canada, Australia, India, and Argentina (FAOSTAT, 2018) accounting to approximately 751 million tons per annum (FAOSTAT, 2018). Yield gains in wheat are currently estimated at about 0.5 to $1 \%$ per year which is below the $2.4 \%$ required to satisfy global demand (Sharma et al., 2012; Crespo-Herrera 
et al., 2018). In order to sustain the fast growing human population, wheat production must increase by at least $50 \%$ by 2030 (Parry et al., 2011). Additionally, the global average wheat yields must increase from 3 to $5 \mathrm{t} \mathrm{ha}^{-1}$, a growth of $1.3 \% \mathrm{yr}^{-1}$ by 2050 to meet demands (Rosegrant and Agcaoili, 2010). Increased wheat production can be achieved through development and cultivation of genotypes with tolerance to abiotic stress and enhanced nutrient, radiation-, and water-use efficiency (WUE). Such genotypes can be developed through identification and selection of drought-adaptive and yield-influencing agronomic and physiological traits, and associated quantitative trait loci (QTL) (Chen et al., 2012; Lopes et al., 2012; Liu et al., 2015).

Grain yield response in wheat is influenced by several agronomic and physiological traits (Chen et al., 2012; Liu et al., 2015). Agronomic traits such as plant height, harvest index (HI), total biomass, number of productive tillers, grain number per spike, spike length (SL), number of kernels per spike, thousand seed weight, and grain weight per spike; and physiological traits such as canopy temperature (CT), chlorophyll content, photosynthetic rate, water-soluble carbohydrates (WSC) have contributed to grain yield improvement in wheat (Foulkes et al., 2007; Lopes et al., 2012; Beche et al., 2014; Chen and Hao 2015; Zhang et al., 2016; Gao et al., 2017). Therefore, there is a need for trait-based breeding using high performing and genetically complementary genotypes to accelerate further grain yield improvement in wheat (Reynolds \& Tuberosa 2008; Chen et al., 2012; Bustos et al., 2013; Liu et al., 2015; Reynolds et al., 2017). The objective of this review is to present breeding progress in wheat for yield gains using agronomic and physiological traits. Globally available wheat genetic resources to aid identification and selection of promising genotypes possessing useful agronomic and physiological traits to enhance water, nutrient-, and radiation-use efficiency to improve grain yield potential and tolerance to abiotic stresses (i.e. elevated $\mathrm{CO}_{2}$, high temperature, and drought) are discussed. Finally, the paper highlights QTL linked to agronomic and physiological traits to aid breeding of high-performing wheat genotypes.

\section{GLOBAL WHEAT PRODUCTION AND YIELD GAINS}

India, Russia, China, and Kazakhstan are currently the leading wheat producers with approximately $30,27,24$, and 12 million hectares devoted to wheat production, respectively. In terms of total production, China is the world's leading wheat producer with approximately 131 million tons per year (FAOSTAT, 2018). Other countries such as Canada, Argentina, Ukraine, and Turkey produce a significantly large amount of wheat (FAOSTAT, 2018). Among African countries, Ethiopia Algeria, Egypt, Kenya, Morocco, and South Africa have the largest area devoted to wheat production with total production above 1 million tons per year. Variable wheat grain yield response per unit area are reported from New Zealand ( 9 tons/ha), Saudi Arabia (6 tons/ha), Zambia (6.6 tons/ha), Egypt (6.5 tons/ha), and China (5.4 tons/ha) in 2016 (FAOSTAT, 2018). The world average wheat yield is 2.9 tons/ha (FAOSTAT, 2018). Worldwide, about 33\% countries achieved yield levels $\leq 2$ tons/ha, while $21 \%$ countries recorded $\geq 3$ tons/ha and $22 \% \geq 5$ tons/ha (FAOSTAT, 2018). Differences in yield levels is attributed to variable climatic conditions, agronomic practices, and genetic potential of cultivars.

Wheat yield gains across the major wheat producing countries are presented in Table 1. Genetic gains estimated through yield trials are variable among modern varieties released at various time periods compared with checks (Graybosch and Peterson, 2010; Lopes et al., 2012; Sharma et al., 2012). This variation is mainly influenced by yield-related agronomic and physiological traits (De Vita et al., 2007; Beche et al., 2014). The highest yield gains were reported in China (123 kg ha-1 $\left.\mathrm{yr}^{-1}\right)$, Chile $\left(246 \mathrm{~kg} \mathrm{ha}^{-1} \mathrm{yr}^{-1}\right)$, France $\left(123 \mathrm{~kg} \mathrm{ha}^{-1} \mathrm{yr}^{-1}\right)$, and Mexico (41.77 $\mathrm{kg} \mathrm{ha}^{-1} \mathrm{yr}^{-1}$ ), whereas relatively lower genetic progress were reported in Spain $\left(24 \mathrm{~kg} \mathrm{ha}^{-1} \mathrm{yr}^{-1}\right)$, Australia $(25 \mathrm{~kg}$ $\left.\mathrm{ha}^{-1} \mathrm{yr}^{-1}\right)$, and Siberia $\left(15.3 \mathrm{~kg} \mathrm{ha}^{-1} \mathrm{yr}^{-1}\right)$. Annual yield gains in Egypt, India, and Pakistan were estimated at $27.4(0.55 \%), 21.4(0.62 \%)$, $111.6(1.13 \%), 32.5(0.83 \%)$, and $18.5 \mathrm{~kg} \mathrm{ha}^{-1} \mathrm{yr}^{-1}(0.5 \%)$, respectively (Sharma et al., 2012). Genetic gains among CIMMYT's spring bread wheat in the Elite Spring Wheat Yield Trial (ESWYT) in the past 15 years (i.e. 1995-2009) in 69 countries showed an annual gain of 27.8 $\mathrm{kg} \mathrm{ha}^{-1}(0.65 \%)$ (Sharma et al., 2012). Countries such as the USA, Chile, France, and Brazil, had reportedly reached maximum limits (Brisson et al., 2010; Graybosch and Peterson, 2010; Matus et al., 2012; Beche et al., 2014).

Genetic progress is relatively lower under low-yielding environments compared to high-yielding environments (Lopes et al., 2012; Joudi et al., 2014; Keser et al., 2017; Crespo-Herera et al., 2018). Therefore, targeted breeding for low-yielding environments (e.g. under drought stressed environments) is crucial to improve grain yield. Differences in rates of genetic progress across different breeding programmes suggest that newly developed and highyielding genotypes possess different genetic and adaptation mechanisms to reach their yield potentials (Gummadov et al., 2015).

Genetic gains in grain yield have been attributed to development and deployment of high-yielding wheat genotypes with improved agronomic and physiological traits related with high yield potential (De Vita et al., 2007; Lopes et al., 2012; Manes et al., 2012; Aisawi et al., 2015; Zhang et al., 2016; Gao et al., 2017). For example, in Mexico genetic gains in grain yield were associated with fewer days to heading, cooler, and reduced CTs at grain filling, increased stay-green, and thousand kernel weight (Lopes et al., 2012). Similarly, significant yield increases in China resulted from increased grain number per spike, thousand kernel weight, HI, and plant height (Zhang et al., 2016). Genetic gains among CIMMYT's spring wheat cultivars developed between 1966 and 2009 in Mexico was associated with increased aboveground dry matter and increased seed weight (Lopes et al., 2012; Aisawi et al., 2015). Further improvement in wheat genetic gains is likely to be realized through breeding for important yieldrelated agronomic and physiological traits.

\section{USE OF AGRONOMIC TRAITS IN PHENOTYPING WHEAT}

Grain yield in wheat is influenced by several agronomic traits (Chen et al., 2012; Liu et al., 2015) which have been widely 
TABLE 1 | Global yield gains in wheat.

\begin{tabular}{|c|c|c|c|c|c|}
\hline Country & Years & $\begin{array}{l}\text { Yield change } \\
\text { (tons/ha) }\end{array}$ & $\begin{array}{l}\text { Mean yield increment } \\
\left(\mathrm{kg} \mathrm{ha}^{-1} \mathrm{yr}^{-1}\right)\end{array}$ & Genetic gain $\left(\% \mathrm{yr}^{-1}\right)$ & Reference \\
\hline Canada & $1885-2008$ & --- & 8.0 & --- & Kamran et al. (2013a) \\
\hline Canada & $2005-2014$ & $2.7-3.1$ & 35.7 & --- & Perez-Lara et al. (2016) \\
\hline China & $1981-2008$ & --- & 51.30 & 0.60 & Zheng et al. (2011) \\
\hline China & $1962-2006$ & --- & $62 \mathrm{~kg}$ & 0.85 & Xiao et al. (2012) \\
\hline China & $1960-2000$ & --- & 32.07 to 72.11 & 0.48 to 1.23 & Zhou et al. (2007a) \\
\hline China & $1949-2000$ & --- & 13.96 & 0.31 & Zhou et al. (2007b) \\
\hline China & $1940-2010$ & --- & 22.8 & 0.48 & Sun et al. (2014) \\
\hline China & $1975-2007$ & --- & 103.5 & 1.09 & Zhang et al. (2016) \\
\hline China & $1950-2012$ & $5-8.5$ & 57.5 & 0.7 & Gao et al. (2017) \\
\hline China & 1945- 2010 & $6.08-7.37$ & 66.0 & --- & Wu et al. (2014) \\
\hline Mexico & 1977-2008 & --- & $3.5 \mathrm{~g} \mathrm{~m}^{-2} \mathrm{yr}^{-1}$ & 0.7 & Lopes et al. (2012) \\
\hline Mexico & 1977-2008 & --- & $6.4 \mathrm{~g} \mathrm{~m}^{-2} \mathrm{yr}^{-1}(\mathrm{HYE})$ & 0.9 & Lopes et al. (2012) \\
\hline Mexico & 1977-2008 & --- & $3.0 \mathrm{~g} \mathrm{~m}^{-2} \mathrm{yr}^{-1}(\mathrm{IME})$ & 0.7 & Lopes et al. (2012) \\
\hline Mexico & 1977-2008 & --- & $1.0 \mathrm{~g} \mathrm{~m}^{-2} \mathrm{yr}^{-1}$ (LYE) & 0.5 & Lopes et al. (2012) \\
\hline Mexico & 1994-2010 & 1.76 to 2.88 (LYE) & 31.0 & 0.5 & Lopes et al. (2012) \\
\hline Mexico & 1994-2010 & 3.78 to 6.02 (HYE) & --- & 1.0 & Lopes et al. (2012) \\
\hline Mexico & 1966-2009 & --- & 30 (HYE) & 0.59 & Aisawi et al. (2015) \\
\hline Mexico & 2002-2003 & 0.15 to 3.5 & 38.13 (LYE) & --- & Crespo-Herrera et al. (2018) \\
\hline USA & 1950-2009 & --- & 37.0 & 0.98 & Green et al. (2012) \\
\hline USA & $1959-2008$ & --- & --- & 1.1 & Graybosch and Peterson (2010) \\
\hline USA & $1874-2000$ & --- & 10.4 & 0.48 & Fufa et al. (2005) \\
\hline USA & $1971-2008$ & --- & 14.6 & 0.93 & Battenfield et al. (2013) \\
\hline USA & 1968-2002 & --- & 30.4 & 1.3 & Underdahl et al. (2008) \\
\hline Brazil & 1940-2009 & $0.17-2.14$ & 29.0 & 0.92 & Beche et al. (2014) \\
\hline Brazil & 1999-2009 & --- & 16.0 & 0.45 & Beche et al. (2014) \\
\hline Brazil & 1998-2014 & --- & 34.8 & 1.0 & Bornhofen et al. (2018) \\
\hline United Kingdom & 1972-1995 & --- & $0.12 \mathrm{Mg} \mathrm{ha}^{-1} \mathrm{yr}^{-1}$ & --- & Shearman et al. (2005) \\
\hline United Kingdom & $1982-2007$ & --- & 74.0 & --- & Mackay et al. (2011) \\
\hline Spain & 1988-2000 & --- & 24.0 & --- & Royo et al. (2007) \\
\hline Spain & 1980-2009 & --- & 24.0 & 0.44 & Chairi et al. (2018) \\
\hline Italy & $1900-1990$ & --- & 19.9 & --- & De Vita et al. (2007) \\
\hline Italy & $1950-2000$ & --- & 25.6 & --- & Giunta et al. (2007) \\
\hline Australia & 1958-2007 & $4.1-6.1$ & 25.0 & --- & Sadras and Lawson (2011) \\
\hline Australia & $1958-2007$ & --- & 18.0 & --- & Sadras and Lawson (2013) \\
\hline Australia & $1901-2014$ & --- & --- & 0.4 & Flohr et al. (2018) \\
\hline Australia & $1958-2011$ & --- & 21.0 & --- & Kitonyo et al. (2017) \\
\hline France & 1950-1996 & --- & 123.0 & --- & Brisson et al. (2010) \\
\hline Siberia & $1900-2000$ & $2.18-3.71$ & 15.3 & 0.7 & Morgounov et al. (2010) \\
\hline Argentina & 1940-1999 & --- & 51.0 & 1.17 & Lo Valvo et al. (2018) \\
\hline Argentina & 1999-2011 & --- & 14.0 & 0.18 & Lo Valvo et al. (2018) \\
\hline Iran & 1930-2006 & --- & 31.0 & --- & Joudi et al. (2014) \\
\hline Iran & 1930-2006 & --- & 20.0 & --- & Joudi et al. (2014) \\
\hline Chile & $1965-2001$ & --- & 246.0 & 2.6 & Matus et al. (2012) \\
\hline France & 1970-2010 & $0.065-0.137$ & 0.114 & --- & Oury et al. (2012) \\
\hline Turkey & $1931-2006$ & $2.9-3.8$ & 12.5 & 0.50 & Keser et al. (2017) \\
\hline Turkey & $1931-2006$ & $0.6-1.8$ & 6.1 (LYE) & 0.66 & Keser et al. (2017) \\
\hline Turkey & $1931-2006$ & $4.0-5.1$ & 18.0 (LYE) & 0.49 & Keser et al. (2017) \\
\hline Turkey & 1963- 2004 & $4.1-5.5$ & 58.0 (HYE) & 1.37 & Gummadov et al. (2015) \\
\hline
\end{tabular}

LYE, Low-yielding environment; IME, Intermediate-yielding environment; HYE, High-yielding environment.

explored in wheat improvement programmes to accelerate cultivar development. Due to their high heritability and correlation with grain yield, agronomic traits can be used as indirect selection criteria during breeding and cultivar development (Table 2) (Chen et al., 2012; Abdolshahi et al., 2015; Liu et al., 2015; Gao et al., 2017). Moreover, it has been suggested that genetic progress in yield can be achieved if several traits conferring better agronomic and physiological performance with biotic and abiotic stress tolerance are simultaneously selected and introgressed in a single variety (Lopes et al., 2012). Some important agronomic traits that have been exploited in wheat improvement programmes to aid cultivar development and increase grain yield potential and genetic gains are discussed below.

\section{Early Flowering and Maturity}

Breeding novel wheat genotypes with early flowering and maturity is an important objective in wheat breeding programmes (Chen et al., 2016; Mondal et al., 2016; Ochagavía et al., 2018). The focus is developing early maturing wheat genotypes as an adaptive mechanism for environments experiencing terminal heat and drought stress (Motzo and 
TABLE 2 | Increased (+), reduced (-), no change (\#) or not yet known (?) effect of selected height reducing, photoperiod and vernalization genes on key agronomic traits in wheat.

\begin{tabular}{|c|c|c|c|c|c|c|c|c|c|c|c|}
\hline Gene name & DH & PH & $\mathrm{HI}$ & BM & FLL & FLW & FLA & TKW & GNPS & GY & References \\
\hline \multicolumn{12}{|l|}{ Plant height } \\
\hline Rht1 & $?$ & - & $?$ & - & $?$ & $?$ & $?$ & $?$ & + & + & Grover et al. (2018) \\
\hline Rht4 & $?$ & - & $?$ & - & + & + & + & - & - & - & Du et al. (2018) \\
\hline Rth4 & $?$ & - & \# & $?$ & $?$ & $?$ & $?$ & - & + & \# & Liu et al. (2017) \\
\hline Rht4 & $?$ & - & + & + & $?$ & $?$ & $?$ & $?$ & + & + & Rebetze et al. (2012a) \\
\hline Rht5 & $?$ & + & - & $?$ & $?$ & $?$ & $?$ & - & - & - & Chen et al. (2018a) \\
\hline Rht5 & - & - & $?$ & $?$ & $?$ & $?$ & $?$ & $?$ & - & $?$ & Daoura et al. (2014) \\
\hline Rht5 & + & - & $?$ & $?$ & $?$ & $?$ & $?$ & $?$ & - & $?$ & Rebetze et al. (2012a) \\
\hline Rht8 & $?$ & - & + & - & $?$ & $?$ & $?$ & + & $?$ & - & Wang et al. (2015) \\
\hline Rht8 & $?$ & - & $?$ & $?$ & $?$ & $?$ & $?$ & $?$ & $?$ & $?$ & Rebetze et al. (2012a) \\
\hline Rht8 & $?$ & - & $?$ & - & $?$ & $?$ & $?$ & $?$ & $?$ & $?$ & \\
\hline Rht8c & $?$ & - & $?$ & $?$ & $?$ & $?$ & $?$ & $?$ & + & $?$ & Rebetze et al. (2012b) \\
\hline Rht12 & $?$ & - & + & + & $?$ & $?$ & $?$ & $?$ & + & + & Rebetze et al. (2012a) \\
\hline Rht13 & $?$ & - & $\#$ & - & $?$ & $?$ & $?$ & $\#$ & $\#$ & - & Wang et al. (2015) \\
\hline Rht13 & $?$ & - & $?$ & $?$ & - & $?$ & $?$ & $?$ & $?$ & $?$ & Wang et al. (2014) \\
\hline$R h t 13$ & $?$ & - & + & $?$ & $?$ & $?$ & $?$ & $?$ & + & $?$ & Rebetze et al. (2011) \\
\hline Rht13 & $?$ & - & + & + & $?$ & $?$ & $?$ & $?$ & + & + & Rebetze et al. (2012a) \\
\hline Rht18 & $?$ & - & + & - & $?$ & $?$ & $?$ & - & + & - & Yang et al.(2015) \\
\hline$R h t B 1 b$ & $?$ & - & $?$ & $?$ & $?$ & $?$ & $?$ & $?$ & + & $?$ & Rebetze et al. (2012a) \\
\hline$R h t B 1 b$ & $?$ & - & + & - & $?$ & $?$ & $?$ & - & + & + & Liu et al. (2017) \\
\hline RhtD1b & $?$ & - & $?$ & $?$ & $?$ & $?$ & $?$ & \# & $?$ & $?$ & Wang et al. (2014) \\
\hline$R h t-B 1 b$ & $?$ & - & $?$ & $?$ & $?$ & $?$ & $?$ & $?$ & + & $?$ & Rebetze et al. (2012b) \\
\hline$R h t-D 1 b$ & $?$ & - & + & + & $?$ & $?$ & $?$ & $?$ & $?$ & + & Rebetze et al. (2012b) \\
\hline \multicolumn{12}{|l|}{ Vernalization } \\
\hline Vrn-B1 & \# & \# & \# & \# & \# & \# & $\#$ & \# & \# & \# & Chen et al. (2018a) \\
\hline \multicolumn{12}{|l|}{ Photoperiod } \\
\hline Ppd-D1 & - & - & + & $?$ & $?$ & $?$ & $?$ & + & + & + & Chen et al. (2018a) \\
\hline$P p d-A 1$ & + & $?$ & + & $?$ & $?$ & $?$ & $?$ & $?$ & $?$ & + & Royo et al. (2018) \\
\hline$P p d-A 1 b$ & + & $?$ & $?$ & + & $?$ & $?$ & $?$ & $?$ & $?$ & \# & Royo et al. (2018) \\
\hline Ppd-B1b & + & $?$ & $?$ & + & $?$ & $?$ & $?$ & $?$ & $?$ & $\#$ & Royo et al. (2018) \\
\hline \multicolumn{12}{|l|}{ Combinations } \\
\hline$P p d-A 1 b+P p d-B 1 b$ & - & $?$ & + & $?$ & $?$ & $?$ & $?$ & $?$ & $?$ & + & Royo et al. (2018) \\
\hline Ppd-D1+Rht5 & - & \# & \# & $\#$ & \# & \# & \# & \# & \# & \# & Chen et al. (2018a) \\
\hline Rth4+RhtB1b & $?$ & - & + & $?$ & $?$ & $?$ & $?$ & $?$ & + & + & Liu et al. (2017) \\
\hline$R h t 4+R h t 8$ & $?$ & - & $?$ & + & \# & \# & \# & + & - & + & Du et al. (2018) \\
\hline Rht13+ Rht8 & $?$ & $?$ & $?$ & $?$ & $?$ & $?$ & $?$ & $?$ & - & $?$ & Wang et al. (2015) \\
\hline$R h t 13+R h t D 1 b$ & $?$ & - & $?$ & $?$ & $?$ & $?$ & $?$ & \# & $?$ & $?$ & Wang et al. (2014) \\
\hline$R h t 8 c+R h t-B 1 b$ & $?$ & - & + & + & $?$ & $?$ & $?$ & $?$ & $?$ & + & Rebetze et al. (2012b) \\
\hline$R h t 8 c+R h t-D 1 b$ & $?$ & - & + & + & $?$ & $?$ & $?$ & $?$ & $?$ & + & Rebetze et al. (2012b) \\
\hline
\end{tabular}

DH, Days to heading; PH, plant height; HI, Harvest index; BM, Biomass; FLL, Flag leaf length; FLW, Flag leaf width; TKW, Thousand kernel weight; GNPS, Grain number per spike; GY, Grain yield.

Giunta, 2007; Mondal et al., 2016). Understanding the genetic factors controlling flowering time is essential to manipulate phenological development processes to improve yield potential in wheat (Royo et al., 2018). Most modern wheat genotypes incorporated vernalization and photo-period insensitive genes to promote early flowering and maturity (Chen et al., 2016). Genes conditioning vernalization namely Vrn-A1,Vrn-B1, and $V r n-D 1$ regulate flowering and maturity in wheat (Iwaki et al., 2002). The effect of Vrn loci on heading and maturity, and grain yield potential are ranked as follows: Vrn-A1 $<r n-B 1<V r n-$ D1 (Zheng et al., 2013; Zhang et al., 2014; Ogbonnaya et al., 2017). This resulted in increased days to heading and grain yield under optimal environments, but decreased grain yield under heat prone environments (Zhang et al., 2008; Kamran et al., 2013b; Ogbonnaya et al., 2017).

Wheat breeders have developed genotypes combining vernalization to promote early maturity and improve grain yield potential. Canadian spring wheat cultivars possessed $\mathrm{Vrn}$ A1 gene at a frequency of $94 \%$ (Chen et al., 2016). In Mexico, $V r n-D 1$ was identified in $66 \%$ of wheat cultivars, while $V r n-A 1$, $V r n-B 1$, and $V r n 4$ were present in 41,39 , and $8 \%$ of the cultivars, respectively, either singly or in combination (van Beem et al., 2005). Vrn-D1 allele showed the highest frequency (64\%) among Chinese wheat cultivars followed by Vrn-A1 (Zhang et al., 2008). This indicates that successful breeding using vernalization genes in wheat improvement is variable across different breeding programmes. Breeding strategies to replace the winter-type alleles, especially $V r n-A 1$ and $V r n-D 1$ loci associated with late heading times (Zhang et al., 2008), has been recommended to develop early-flowering cultivars for water-limited environments. Zhang et al. (2014) reported that the genotypes possessing the Vrn-A1avrn-B1Vrn-D1a loci would result in reduced time to anthesis and improve grain yield potential and kernel number in water-stressed environments. Contrastingly, incorporation of 
$V r n-D 1$ is recommended in spring wheat to increase grain yield and improve adaptation to late drought and heat stress tolerance.

Photoperiod sensitive genes namely: Ppd-D1a, Ppd-B1, and $P p d-A 1$ control photoperiod sensitivity impacting on flowering and maturation times in wheat (Gomez et al., 2014; Langer et al., 2014). The effect of selected photoperiod genes on key agronomic traits in wheat are presented in Table 2. Early flowering wheat genotypes with photo-period insensitivity produce high biomass and grain yield, whereas photo-period sensitivity alleles $P p d-$ $A 1 b$ and $P p d-B 1 b$ resulted in lower yields (Royo et al., 2018). Conversely, late flowering response was induced by photo-period sensitivity due to the presence of alleles $P p d-A 1 b$ and $P p d-B 1 b$. This produced high dry matter with little advantage in terms of grain yield potential (Royo et al., 2018). Early maturity achieved through early flowering and maturity resulted in positive genetic gains (DeVitta et al., 2007; Motzo and Giunta, 2007; Morgounov et al., 2010; Kamran et al., 2013a). In some cases, yield increase was not associated with earlier flowering in wheat (Chairi et al., 2018; Flohr et al., 2018). The limited genetic gains incorporating early maturity may be due to reduced time available for assimilate partitioning required for high grain yield development (Royo et al., 2007) partly explained by the negative association between kernel weight per spike and heading date (Zhou et al., 2007a).

The combination of $P p d-D 1$ and dwarfing gene Rht5 were reported to have negligible effect on plant growth, flowering time, spike development, and grain yield in wheat. This suggests that exploiting photoperiod-insensitive and dwarfing genes may improve grain yield by balancing flowering time and yield components (Chen et al., 2018a; Ochagavía et al., 2018). Chen et al. (2018b) reported that Ppd-D1 and Rht5 can shorten the duration of the reproductive phase and facilitate early flowering. $P p d-D 1$ can also reduce plant height, whereas the combination of $P p d-D 1$ and Rht5 resulted in shorter plants with increased lodging resistance (Table 2). Furthermore, Ppd-D1 can increase grain number from 6 to $10 \%, 1,000$ grain weight (13 to $22 \%$ ), grain yield (23 and $40 \%$ ), and $\mathrm{HI}$ (31 and 50\%) from tall and dwarf genotypes, respectively. Canadian spring wheat carrying dominant allele of Vrn-B1, photo-period insensitive allele of $P p d-D 1$, and height reducing allele $R h t-1$ produced shorter plants and higher grain yield (Chen et al., 2016). In some breeding programmes, the photoperiod sensitive gene $P p d-D 1 b$ is being replaced with the photo insensitive gene to develop early maturing genotypes (Kamran et al., 2013b). Vrn-B1 can also act additively with a region on chromosome $2 \mathrm{~B}$ near the $P p d-B 1$ locus, indicating that a shorter vernalization requirement combined with the $P p d-B 1 b$ allele for photoperiod sensitivity may play a key role in wheat adaptation to varied environmental conditions (Addison et al., 2016). Early-maturing, high-yielding, heat-tolerant wheat genotypes with excellent adaptation to diverse environments that incorporated vernalization, photo-period, and dwarfing genes have been developed by CIMMYT and other breeding programmes globally (Chen et al., 2016; Mondal et al., 2016; Royo et al., 2018). Negative and significant correlations exist between days to flowering and grain yield potential suggesting that breeding for high yielding and early-maturing wheat genotypes can further be achieved by manipulating wheat phenology (Kamran et al., 2013b; Mondal et al., 2016). However, such genotypes should have faster growth rates and accumulate sufficient biomass production in shorter times to increase grain yield potential. Molecular markers linked to vernalization and photo-period genes useful for marker- assisted breeding have been identified in wheat (Chen et al., 2016).

\section{Plant Height}

Breeding novel wheat genotypes with reduced plant height has increased genetic gains in wheat and significantly contributed to increased wheat productivity globally (Beche et al., 2014; Gummadov et al., 2015; Würschum et al., 2015; Zhang et al., 2016). Many wheat improvement programmes have developed wheat genotypes incorporating the dwarfing/height reducing genes namely: Rht1 (Rht-B1b), Rht2 (Rht-D1b), Rht-D1c, and Rht8 (Zheng et al., 2011; Green et al., 2012; Lopes et al., 2012; Joudi et al., 2014; Zhang et al., 2016; Chairi et al., 2018). The genes reduce coleoptile and internode length, and plant height (Rebetzke et al., 2011; Rebetzke et al.,2012a,Rebetzke et al., 2012b) resulting in increased grain yield (Grover et al., 2018) by increasing assimilate partitioning to the ear. This resulted in higher HI and lodging resistance (Divashuk et al., 2013). Breeding progress to improve lodging resistance and grain yield in wheat resulted in plant height reduction from 130 to $60 \mathrm{~cm}$ in China (Gao et al., 2017), 110 to $95 \mathrm{~cm}$ in the UK (Berry et al., 2015), 120 to $57 \mathrm{~cm}$ in Italy (De Vita et al., 2007), 130 to $60 \mathrm{~cm}$ in Brazil (Beche et al., 2014), and from 125 to $65 \mathrm{~cm}$ in Spain (Royo et al., 2007) when replacing old by recent and short plant height wheat cultivars. In the USA the genetic progress of breeding for reduced plant height varied from -0.32 to $-0.33 \% \mathrm{yr}^{-1}$ and -0.37 to $-0.43 \% \mathrm{yr}^{-1}$ across varied environments (Graybosch and Peterson, 2010). Zhou et al. (2007a) and Beche et al. (2014) reported a reduction in plant height by -0.69 and $-0.74 \% \mathrm{yr}^{-1}$ among Chinese and Brazilian wheat genotypes, respectively.

To date approximately 24 height reducing genes are reported including Rht-B1b, Rht-B1c, Rht-B1d, Rht-B1e, Rht-B1f, Rht-B1g, Rht-D1b, Rht-D1c, Rht-D1d, Rht4, Rht5, Rht7, Rht8, Rht9, Rht12, Rht13, Rht14, Rht16, Rht18, and Rht21. These genes regulate plant height in wheat (McIntosh et al., 2013). The effect of selected height reducing genes on selected agronomic traits are summarized in Table 2. However, only a few dwarfing genes have been widely utilized for improving yield in wheat (Chen et al., 2015). Knowledge regarding the function of other dwarfing genes is important for breeding (Zhang et al., 2006). Further, opportunities exist for integrating commonly used height reducing genes (i.e. Rht1, Rht2, Rht8) with other dwarfing (GAR) genes such as Rht4, Rht5, Rht11, Rht12, and $R h t 24$ to improve yield and lodging resistance (Ellis et al., 2005; Rebetzke et al., 2012a, Rebetzke et al., 2012b; Chen et al., 2018a; Mo et al., 2018). Combination of Rht-B1e with Rht8 or Rht-B1b with Rht8 reportedly improved grain yield potential (Divashuk et al., 2013). Wheat genotypes with either Rht-B1b $+R h t 8 c$ or $R h t-D 1 b+R h t 8 c$ exhibits higher grain yield, spike number, kernel number, thousand grain weight, above-ground biomass, HI, stem WSCs, chlorophyll content, and reduced plant height (Gao et al., 2017). The combination of Rht4+Rht8 dwarfing genes 
has no effect on leaf length, leaf width, and flag leaf area (FLA) but resulted in reduced grain number per spike and increased 1,000-kernel weight, above-ground biomass and grain yield in wheat (Du et al., 2018). These suggested that combinations of Rht 4 and Rht 8 could reduce plant height to desirable levels, while improving grain yield and yield-related traits in wheat (Du et al., 2018). Similarly, combinations of dwarfing genes Rht4 and $R h t-B 1 b$ reduce plant height and increase grain yield due to increased grain number, greater spike number, and higher $\mathrm{HI}$ in wheat (Liu et al., 2017) suggesting Rht4 can be successfully combined with $R h t-B 1 b$ in wheat improvement to accelerate yield gains (Liu et al., 2017). Similarly, Rht5/Rht8 improved heading date and maturity in wheat (Daoura et al., 2014) useful for breeding and cultivar development (Table 2). Additive gene action was reported between Rht12 and Ppd-D1 such that incorporation of $P p d-D 1 a$ enhanced flowering, and improved yield and yield-related traits of Rht 12 dwarf plants, suggesting that the combination of $R h t 12$ and Ppd-D1a may increase use of Rht12 in wheat breeding (Chen et al., 2018b). Tian et al. (2019) showed that a combination of diverse height reducing genes have already been incorporated in elite Chinese wheat genotypes. For instance, combinations of $R h t 24+R h t 1, R h t 24+R h t 2$, Rht24+Rht8, Rht1+Rht8, Rht2+Rht8, Rht24+Rht1+Rht8, $R h t 24+R h t 2+R h t 8$ occurred at frequencies of $86,117,137,56$, 77,47 , and $70 \%$, respectively in Chinese wheat genotypes.

A dwarfing gene Rht5 has been shown to reduce plant height by approximately $40 \%$ without affecting coleoptile length and seedling vigour (Chen et al., 2018a). However, Rht5 can reduce SL by approximately 16.7 and $22.6 \%$, grain number by 11.5 and $14.5 \%, 1,000$-grain weight by 18.4 and $24.1 \%$ and grain yield by 21.5 and $35.1 \%$ and delayed ear emergence and anthesis time, thus hindering effective utilization in wheat improvement (Chen et al., 2018a). Therefore, genes promoting plant development and flowering times need to be incorporated with Rht5 dwarf lines to exploit their potential in wheat breeding programmes. The combination of $R h t 5$ with other dwarfing genes to improve genetic gains in grain yield remains unexplored and un-investigated (Chen et al., 2018a). Recently, a dwarfing gene Rht25, with Rht25a representing the height-increasing allele and $R h t 25 b$ designated the dwarfing allele were identified in wheat (Mo et al., 2018). The average dwarfing effect of $R h t 25 b$ was found to be approximately half of the effect observed for $R h t-B 1 b$ and $R h t-D 1 b$, and the effect greater in the presence of height-increasing Rht-B1a and Rht-D1a alleles than in the presence of the dwarfing alleles (Mo et al., 2018). Rht25b is gibberellin acid sensitive gene and shows significant pleiotropic effects on coleoptile length, heading date, SL, spikelet number, spikelet density, and grain weight (Mo et al., 2018). Therefore, Rht 25 may serve as an alternative dwarfing gene to improve wheat yield potential across diverse environments (Mo et al., 2018).

Some studies suggested that wheat plant height has reached its theoretical limit at about 70 to $80 \mathrm{~cm}$, suggesting that limited progress will be achieved through further reduction in plant height (Shearman et al., 2005). As a result, plant height cannot be decreased any further to avoid risking reductions in biomass and grain yield (Berry et al., 2015). Therefore, strategic breeding that combines both plant height and grain yield to maximise yield potential and lodging resistance has been suggested (Gao et al., 2017). GAR dwarfing genes, such as Rht4, Rht5, Rht8, Rht11, Rht12, Rht13, Rht24, and Rht25 have the potential to reduce plant height further (Rebetzke et al., 2012a, Rebetzke et al., 2012b; Chen et al., 2018a; Mo et al., 2018). These genes (i.e. Rht4, Rht5, Rht8, Rht11, Rht12, Rht13, Rht24, and Rht25) have negligible effects on biomass production, whereas some (i.e. Rht4, Rht12; Rht13; Rht24) can increase above-ground biomass, kernel weight, and grain yield (Rebetzke et al., 2012a; Rebetzke et al., 2012b; Yang et al., 2015; Würschum et al., 2017; Tian et al., 2019). The Rht24b allele is already used in combination with the two Rht-1b semi-dwarfing genes in wheat breeding (Würschum et al., 2017; Tian et al., 2019). As a result, Rht24 utilization has increased in European countries, China and the USA, indicating that wheat breeders have actively selected for this locus for cultivar development to improve lodging resistance and grain yield potential (Würschum et al., 2017; Tian et al., 2019). Rht24 occurs at a frequency of about $84.2 \%$ than other important dwarfing alleles in elite wheat varieties in China and usually couples with $R h t 2$ or Rht8 (Tian et al., 2019). Similarly, Würschum et al. (2017) also showed that Rht24 occurred at high frequency of approximately 67\% compared with GR genes and $R h t 8$ in $>1,000$ wheat varieties originating mainly from Europe. However, while transferring height reducing genes to well-adapted wheat genotypes, attention should be directed to selection of the most suitable adapted parents as the effect of the gene vary with different genetic backgrounds (Yang et al., 2015). Additionally, very limited information is available detailing the effect of dwarfing genes on wheat physiological processes which may limit effective breeding targeting such traits.

\section{Harvest Index}

HI has accelerated breeding for improved grain yield potential in wheat. For example, $\mathrm{HI}$ in wheat improved from approximately 0.25-0.44 (Gao et al., 2017) and 0.26-0.55 (Zhang et al., 2016) in China, 0.42-0.46 in the USA (Green et al., 2012), 0.26-0.42 in Spain (Royo et al., 2007), 0.21-0.43 in Australia (Flohr et al., 2018), 0.41-0.43 in Italy (Giunta et al., 2007), and 0.28-0.36 in Turkey (Gummadov et al., 2015). Additionally, gains in HI increased at an average of 0.51 and $0.63 \% \mathrm{yr}^{-1}$ in China (Zhou et al., 2007a; Gao et al., 2017), 0.19\% $\mathrm{yr}^{-1}$ in Italy (Giunta et al., 2007), and 0.11 and $0.002 \% \mathrm{yr}^{-1}$ in Australia (Sadras and Lawson, 2011; Flohr et al., 2018). Despite significant improvement in HI, the trait has remained at approximately 0.55 which is below a theoretical limit of 0.62 (Gaju et al., 2009). In China, HI of some widely cultivated cultivars released between 1945 and 2010 have reportedly reached their theoretical maximum limit suggesting future gains in yield may depend on achieving greater harvest biomass production, while maintaining HI (Shearman et al., 2005). Linear and positive relationship was observed between HI with grain yield over time suggesting that $\mathrm{HI}$ can improve yield gains even further (Zheng et al., 2011).

\section{Biomass Production}

Increased biomass has resulted in grain yield improvement in wheat. The increase in biomass has been largely attributed to 
higher photosynthetic rate, stomatal conductance, leaf chlorophyll content and improved radiation-use efficiency (Bustos et al., 2013). It has been suggested that further improvements in grain yield can be achieved by increasing photosynthetic capacity by optimizing biomass production while maintaining lodging resistance (Beche et al., 2014). Several studies showed that biomass contributed significantly to increased grain yield (Shearman et al., 2005; Xiao et al., 2012; Bustos et al., 2013; Aisawi et al., 2015; Gao et al., 2017), whereas others studies indicated very little contribution of this trait (Royo et al., 2007; Tian et al., 2011; Zheng et al., 2011; Sun et al., 2014; Zhang et al., 2016). In China, Gao et al. (2017) reported that biomass accumulation significantly increased by $0.39 \% \mathrm{yr}^{-1}$ or $62.6 \mathrm{~kg} \mathrm{ha}^{-1}$ $\mathrm{yr}^{-1}$, among new Chinese wheat cultivars. Reynolds et al. (2017) reported that crossing complementary genotypes exhibiting high biomass and HI may improve yield gains in wheat than crossing only high yielding genotypes. Zheng et al. (2011) also reported that further increases in above-ground biomass and HI may continue to contribute to grain yield improvement in genotypes within optimum plant height. However, the negative relationship between plant height with $\mathrm{HI}$ and biomass may offset such gains. In some instances, positive association has been reported (Aisawi et al., 2015) which further suggests manipulation of this trait can improve genetic gains in grain yield even further.

\section{Kernel Weight}

Grain yield improvement has been significantly associated with increased thousand kernel weight (TKW) (Zhou et al., 2007a; Morgounov et al., 2010; Tian et al., 2011; Zheng et al., 2011; Lopes et al., 2012; Aisawi et al., 2015). On the contrary, non-significant contribution of TKW were reported (Shearman et al., 2005; Royo et al., 2007; Acreche et al., 2008; Brisson et al., 2010; Xiao et al., 2012) especially under heat stress condition limiting the selection response for this trait under low-yielding environments (Sharma et al., 2012; Lopes et al., 2012). Improvement in TKW ranged from 39 to $55 \mathrm{~g}$ (Gao et al., 2017) and 29 to $49 \mathrm{~g}$ (Zhang et al., 2016) among old landrace varieties and newly-developed Chinese wheat genotypes. Similarly, Giunta et al. (2007) reported TKW of 33 to $54-55 \mathrm{mg}$ in old cultivars and 41 to $57 \mathrm{mg}$ in modern wheat cultivars. In the USA, Underdahl et al. (2008) also reported improvement in TKW ranging between 20.4 to $33.6 \mathrm{~g}$ for old (i.e. 1973) and newly released (i.e. 2004) cultivars, respectively. Additionally, Gao et al. (2017) and Underdahl et al. (2008) reported genetic gains of $0.35 \% \mathrm{yr}^{-1}\left(0.18 \mathrm{~g} \mathrm{yr}^{-1}\right)$ and $0.3 \%$ $\mathrm{yr}^{-1}$ for TKW among Chinese and American wheat genotypes, respectively. Similarly, Beche et al. (2014) reported increased TKW of $0.03 \mathrm{~g} \mathrm{yr}^{-1}$ among Brazilian wheat genotypes. TKW is reportedly linear with moderate to high correlation with grain yield (Morgounov et al., 2010; Zheng et al., 2011; Qin et al., 2015; Gao et al., 2017) suggesting selection of heavier grains could be highly effective for improving wheat yield gains. As a result, increasing grain weight potential at specific positions within the spikelet has been suggested (Calderini and Reynolds, 2000), rather than breeding for higher TKW. Breeding for high grain number and TKW in the same genotype has been reported to be difficult due to trade-offs. Gaju et al. (2009) suggested trade-off can be minimized by selecting genotypes with higher number of spikelets per spike (SPS). These authors showed that genotypes with high spikelet number resulted in spikes with higher grain number and heavier TKW. An alternative approach involving crossing of suitable genotypes possessing contrasting grain number and grain weight to combine both traits in the progeny has also been proposed by Bustos et al. (2013). These authors reported an increase in grain yield combining both traits confirming the possibility that crossing genotypes expressing high grain number with those expressing high TKW (and with similar yield and biomass) might be a useful strategy to increase yield potential in wheat.

\section{Number of Grains Per Spike}

The number of grains per spike has been identified as an important trait for improving grain yield (Yu et al., 2014; Alonso et al., 2018; Würschum et al., 2018; Liu et al., 2018c). Yield gains resulting from improvement in grain number has been reported, (Tian et al., 2011; Flohr et al., 2018; Liu et al., 2018c) suggesting successful selection in wheat breeding (Xiao et al., 2012; Aisawi et al., 2015); whereas in some instances it was not associated with genetic progress in grain yield (Zhou et al., 2007a; Xiao et al., 2012; Gao et al., 2017). Chairi et al. (2018) reported grain yield increases of $24 \mathrm{~kg} \mathrm{ha}^{-1} \mathrm{y}^{-1}\left(0.44 \% \mathrm{yr}^{-1}\right)$ between 1980 and 2003 attributed to high number of kernels spike ${ }^{-1}\left(0.24\right.$ kernels spike ${ }^{-1}$ $\mathrm{yr}^{-1}$ ) in Spain. Similarly, Joudi et al. (2014) reported improvement of grain number per spike of 35 grains $\mathrm{m}^{-2} \mathrm{yr}^{-1}$ through breeding and selection spanning over 50 years in Iran. Grain number among Brazilian wheat genotypes was increased by 77.89 grains $\mathrm{yr}^{-1}$. In China grain number per spike varied between 26 for landraces developed in 1941 to 38 for improved wheat genotypes released between 2007 and 2011 (Zhang et al., 2016). Among wheat cultivars developed in the USA, number of grains per spike varied between 25 and 38 for old and modern cultivars (Green et al., 2012). Although indirect selection for genotypes with a higher grain number has been effective, the negative correlation between the number of grains per spike and thousand kernel weight suggests that further increases in number of grains would be partially offset by reductions in grain weight (Sadras and Lawson, 2011; Bustos et al., 2013). Therefore, an increase in the number of spikelets can be selected concurrently with increased SL, to offset an increase in spike compactness (SC) (Würschum et al., 2018). The relationship between grain yield and grain number is reportedly curvilinear in some instances suggesting that the strategy for increasing grain yield through higher grain number could be less efficient (Sadras and Lawson, 2011; Bustos et al., 2013). On the contrary, the linear relationship reported between grain number per spike and grain yield suggest the likelihood of this trait in improving grain yield potential in some instances (Tian et al., 2011; Qin et al., 2015).

\section{Spike Fertility}

Spike fertility (SF) is a grain yield component that influences the increase in the number of kernels per spike (Reynolds et al., 2017; Würschum et al., 2018). For instance, selection for SF either solely 
or in combination results in higher grain yield, than selecting for high yield alone (Alonso et al., 2018). Increase in the number of kernels per spike were attributed to increased SF (Würschum et al., 2018). In addition, SF is a highly heritable trait, controlled by several genes with additive effects (Alonso et al., 2018). Number of kernels per spike and spikelet fertility are significantly and positively correlated but negatively correlated with kernel weight (Würschum et al., 2018). These suggested increase in either number of kernels per spike and spikelet fertility will likely reduce TKW and grain yield potential in wheat. This effect suggests that improvement in grain yield can be achieved through an integrated approach targeting several yield-component traits (Würschum et al., 2018). Novel wheat genotypes possessing large spikes (e.g. high assimilate partitioning to spike, long rachis, high spikelet number per spike, high fertile florets per spikelet) are maintained by CIMMYT useful of breeding (Gaju et al., 2009). In China, wheat genotype Zhongmai 895 released in 2012 with a yield potential at $8,906 \mathrm{~kg} \mathrm{ha}^{-1}$ was derived from 'Zhoumai 16 ' $\mathrm{x}$ 'Liken 4'. Zhoumai 16 was developed from 'Yumai 21' x 'Zhou $8425 B$ ' whereby Zhou $8425 B$ is characterized by large spikes and high TKW (Gao et al., 2017), demonstrating the feasibility of incorporating large spikes in wheat improvement programmes.

Other spike characteristics useful for breeding include SL, SPS, and SC (Chairi et al., 2018; Würschum et al., 2018). The number of kernels per spike is positively and moderately correlated with SPS and SL; whereas SL is positively correlated to SC (Würschum et al., 2018). Spike characteristics are highly heritable traits with heritability values of 0.90 for SL, 0.92 for SPS, 0.93, and 0.67 for SC (Würschum et al., 2018). De Vita et al. (2007) reported that SL and SPS did not improve grain yield potential of durum wheat cultivars released in Italy between 1900 and 1990. The contribution of other spike traits as selection criterion for advancing grain yield genetic gains in wheat are yet to be explored.

\section{Number of Productive Tillers}

Number of productive tillers defined as the number of tillers that produce spikes and seeds is a key agronomic trait that affect biomass production and grain yield potential in wheat (TauszPosch et al., 2015). Wheat genotypes with reduced tillering capacity are more productive than free-tillering genotypes under drought stressed conditions (Naruoka et al., 2011; Wang et al., 2016; Houshmandfar et al., 2019) due to reduced sterile spikelets (Gaju et al., 2014). Contrastingly, Sadras and Rebetzke (2013) reported that lines possessing the free-tillering allele showed increased tiller production which was related to increased grain yield potential under high-yielding environments. Several tiller inhibition genes (Duggan et al., 2005; Mitchell et al., 2012; Wang et al., 2018) and tiller promoting genes (Naruoka et al., 2011) have been identified in wheat useful for improving wheat grain yield. Tin1 tiller inhibition gene can increase grain number per spike (Duggan et al., 2005; Gaju et al., 2014) and HI from 0.31 to 0.35 (Motzo et al., 2004). Therefore, the introgression of the Tin 1 gene into modern wheat germplasm may offer opportunities to increase grain number per spike, grain $\mathrm{m}^{-2}, \mathrm{HI}$, and ultimately grain yield improvement in wheat (Gaju et al., 2014).

\section{Leaf Morphology and Its Component Traits}

Optimal flag leaf morphology can improve light absorption, which improves photosynthesis and grain yield potential (Liu et al. 2018a). Leaf traits such as flag leaf angle (FLAN), flag leaf width (FLW), flag leaf length (FLL), the ratio of length/width of flag leaf (FLR), and FLA may be useful for improving grain yield in wheat. FLL, FLW, and FLA are correlated with some important agronomic traits (Liu et al., 2018 a, b). Additionally, FLL, FLW, and FLA have been reported to be significantly and positively correlated to SL, grain weight per spike, and grain number per spike (Fan et al., 2015; Liu et al. 2018a; Liu et al. 2018b Wu et al., 2016; Zhao et al., 2018) indicating leaf traits influence yield-related traits (Liu et al., 2018a). Wheat genotypes with relatively larger flag leaf size tends to produce more kernel number per spike (Zhao et al., 2018), suggesting appropriate flag leaf size could promote development of high grain yield potential. FLA is reportedly the most yield contributing trait, followed by FLW and FLL (Fan et al., 2015). In the USA, Balota et al. (2017) reported that yield gains in soft red winter wheat genotypes developed between 1919 to 2009 were associated with reduced leaf area suggesting yield increases were achieved through selection of smaller leaf size. Broad-sense heritability for FLAN, FLW, FLL, FLR, and FLA are reportedly higher (> 70\%), indicating that flag leaf traits could be targeted for breeding and cultivar development (Wu et al., 2016; Liu et al., 2018a).

\section{Root and Root-Related Traits}

Root system development and its component traits are useful attributes to extract water from deeper soil profile under water-limited conditions. These traits are associated with heat and drought stress adaptation (Lopes and Reynolds, 2010; Pinto and Reynolds, 2015; Merchuk-Ovnat et al., 2016). Therefore, root and root-related traits can be integrated in wheat improvement programmes for cultivar development. Enhanced root development (based on root dry weight analysis) in wheat is negatively correlated with WSCs under drought-stress condition indicating extensive root development enhances drought tolerance by accumulation of carbohydrates (Lopes and Reynold, 2010; Mkhabela et al., 2019). Root-related traits such as root: shoot ratio negative relationship with agronomic traits such as plant height, number of tillers, shoot biomass, thousand grain weight, and grain yield. This suggests that reduced root development may be negatively associated with yield gains under waterstressed environments (Bai et al., 2013; Mathew et al., 2018). Root traits including root biomass are positively correlated to number of grains per spike and grain yield (Ehdaie et al., 2016). This suggests that root development contributes to yield and yield-related traits expression. Yield gains under waterstressed conditions have been attributed to enhanced capacity of new breeds of wheat to extract water from deeper soil profile (Pask and Reynolds, 2013). The ability to extract water from deeper soil horizon during moisture deficit condition is attributed to development of deeper and vigorous root system. This is accompanied by enhanced stomatal conductance and 
transpiration rates, and reduced CT resulting in higher grain yield and biomass production (Pask and Reynolds, 2013). Despite the direct influence of root and root-related traits on drought tolerance there is limited information on their role on yield gains in wheat breeding programs. Further, whether changes in yield gains could be related to root component traits in wheat is not clearly understood.

\section{PHENOTYPING BASED ON PHYSIOLOGICAL TRAITS IN WHEAT}

Knowledge of physiological traits associated with genetic gains in yield is important for breeding (Beche et al., 2014; Aisawi et al., 2015; Zhang et al., 2016). It has been reported that breeding wheat genotypes incorporating physiological traits can improve grain yield genetic gains by approximately $50 \%$ (Reynolds et al., 2012). Physiological traits that have contributed to grain yield improvement in wheat are discussed below.

\section{Canopy Temperature}

CT has significantly played a key role in improving yield potential in wheat (Lopes and Reynolds, 2010; Lopes et al., 2012; Gao et al., 2017). Cooler plant canopy during mid-grain filling is linked to higher drought tolerance and yield under water-limited condition (Thapa et al., 2018). Breeding genotypes with reduced $\mathrm{CT}$ resulted in lowering this trait from 30 to $29^{\circ} \mathrm{C}$ in CIMMYT spring bread wheat programme spanning over 30 years (Lopes et al., 2012). Similarly, genetic gains in CT increased by $0.12 \%$ $\mathrm{yr}^{-1}$ among Chinese wheat cultivars (Gao et al., 2017). Further, a significant negative linear relationship existed between CT and grain yield with year of cultivar release (Lopes et al., 2012; Pinto et al., 2017; Thapa et al., 2018) indicating possibilities to reduce CT further to increase grain yield in wheat (Lopes et al., 2012).

\section{Chlorophyll Content}

Chlorophyll content is useful trait for breeding for high grain yield potential in wheat. Several reports have shown some breeding progress incorporating this trait with new wheat cultivars showing slightly high chlorophyll content than old cultivars (Beche et al., 2014). Increased post-anthesis chlorophyll content is positively and moderately correlated with $\mathrm{HI}$, leaf CT, water soluble carbohydrates, and grain yield (Lopes et al., 2012; Gao et al., 2017). The stay-green trait which is related to retention of chlorophyll content has been identified as a key target trait for improving light interception and utilization and can contribute to increased wheat yield (Cossani and Reynolds, 2012). Similarly, Lopes and Reynolds (2012) showed that stay-green was correlated with yield under heat stress and heat combined with drought in spring wheat. Therefore, selection for stay-green trait in promising wheat genotypes will likely increase the rate of genetic progress for adaptation of wheat under both well-watered and water-limited environments (Christopher et al., 2018). The linear association reported between stay-green trait and grain yield improvement suggest the latter can be targeted for cultivar development (Lopes et al., 2012; Beche et al., 2014).

\section{Enhanced Photosynthetic Capacity}

Understanding changes in photosynthetic capacity among elite wheat genotypes is important for improving yield gains (Parry et al., 2011; Zheng et al., 2011; Reynolds et al., 2012). In China, changes in leaf photosynthesis were not associated with improved grain yield in 70 years of wheat improvement (Chen and Hao 2015). The lack of correlation between genetic changes in photosynthetic rate and yield increase suggests that leaf photosynthesis does not limit/improve grain yield development or that cultivar development has not specifically targeted improved photosynthetic capacity. As result, determinants of sink strength should be targeted for increasing yield rather than selection for higher photosynthetic rates under drought stress condition (Chen and Hao, 2015). Conversely, genetic gains in rates of post-anthesis net photosynthesis were closely and positively correlated with grain yield (Zheng et al., 2011; Beche et al., 2014). Fischer et al. (1998) also reported that wheat yield gains were associated with higher stomatal conductance and increased photosynthetic rate. Other photosynthesis-related traits such transpiration rate, stomatal conductance or WUE were reported non-influential on yield development (Chen and Hao, 2015) whereas other studies (i.e. Sayre and Rajaram, 1997; Beche et al., 2014) reported improved genetic gains. CIMMYT's heat and drought tolerant wheat genotypes showed genetic gains in yield with correlation to physiological traits (Lopes et al., 2012). Positive relationships have been reported between photosynthetic rate and chlorophyll content suggesting increased chlorophyll content improves photosynthetic efficiency (Zhang et al., 2009). Positive correlations have been reported between photosynthetic rate with stomatal conductance and biomass production (Beche et al., 2014) suggesting enhanced stomatal conductance and photosynthetic rate increases the rate of biomass accumulation (Parry et al., 2011). To improve photosynthetic efficiency, crosses can be conducted between adapted wheat cultivars with those exhibiting high-photosynthetic rates. Higher yield levels can be achieved by integrating photosynthesis related traits (e.g. stomatal conductance and transpiration rate) with yield-related agronomic traits (Zhang et al., 2016) to develop genotypes with higher yield potential (Rebetzke et al., 2013).

\section{Water Soluble Carbohydrates}

WSC significantly improved yield gains in wheat (Shearman et al., 2005; Foulkes et al., 2007; Gao et al., 2017). In addition, significant correlations with grain yield have been reported between radiation-use efficiency and WSC in wheat (Shearman et al., 2005; Foulkes et al., 2007), which suggested that genetic gains in wheat yield is driven by improved growth rate due to increased accumulation of WSC (Shearman et al., 2005). Sadras and Lawson (2011), and Gao et al. (2017) reported genetic gains in WSC of 0.12 and $0.81 \% \mathrm{yr}^{-1}$ among Australian and Chinese wheat genotypes, respectively. Genotypes with high WSC are commonly shorter, flower and mature earlier, and 
produce significantly fewer tillers than those with low WSC (Rebetzke et al., 2008), suggesting cultivar development targeting incorporation of plant height (e.g. Rht-B1) and/or anthesis date genes (e.g. $P p d 1$ ) resulted in improvement of WSC. In addition, wheat genotypes with high WSC produce more fertile tillers, reduced days to anthesis, increased biomass, grain number, and grain yield than genotypes with low WSC (Rebetzke et al., 2008). Grain weight is high in genotypes with high WSC during early grain filling stages, indicating that more available assimilates contribute to higher grain weight potential (Dreccer et al., 2009). Further, WSC accumulation ability and remobilization efficiency in drought tolerant cultivars is much higher than those in sensitive wheat genotypes (Hou et al., 2018) suggesting increased WSC enhances drought tolerance in wheat (Hou et al., 2018). It has been suggested that cultivar development may have targeted improvement of photosynthetic efficiency which has driven increases in number of grains and a larger source for grain filling through increases in stem WSC (Shearman et al., 2005). Moderate to high heritability of WSC (Ruuska et al., 2006; Rebetzke et al., 2008) suggest breeding for either high or low concentration of WSC is possible.

\section{WHEAT GENETIC RESOURCES FOR IMPROVING WHEAT GRAIN YIELD GENETIC GAINS}

Exploration of wheat genetic resources is useful to identify sources of variation for agronomic and physiological traits and discovery of new alleles for improving grain yield potential (Zhang et al., 2016; Reynolds et al., 2017; Liu et al., 2018c). Wheat genetic resources including landrace varieties, synthetic cultivars, and wild relatives including Triticum tauschii L. and wild emmer wheat ( $T$. dicoccoides Korn $(2 \mathrm{n}=28$, AABB) possess useful source of alleles for enhancing drought tolerance and improving yield and its component traits (Gororo et al., 2002; Moeller et al., 2014; Cossani and Reynolds, 2015; Gaju et al., 2016; Merchuk-Ovnat et al., 2016; Pinto et al., 2017; Reynolds et al., 2017; Liu et al., 2018c). In China, about 48 improved wheat genotypes released between 2011 and 2016 were developed using synthetic wheat (Liu et al., 2018c). Synthetic wheat genotypes with high biomass and yield expression, and physiological traits such as higher leaf photosynthetic rate and lower leaf transpiration rates have been identified (del Blanco et al., 2000; Reynolds et al., 2015; Pinto et al., 2017). Modern high-yielding cultivars that incorporated genes from syntheticwheat tend to have higher gas exchange rates compared to older cultivars (De Vita et al., 2007; Sadras and Lawson, 2011; Xiao et al., 2012; Beche et al., 2014). Cossani and Reynolds (2015) identified a set of advanced wheat lines derived from synthetic hexaploid wheat with high levels of heat tolerance incorporating several drought adaptive mechanisms such as such as higher crop growth rate, increased WSCs storage in stems, cooler CT, and spectral indices which are related to pigment composition, photo-protective mechanisms, and increased radiation use efficiency. These traits result in increased number of grains, growth of taller stems with a greater WSCs storage capacity significantly related to increased kernel weight (Cossani and Reynolds, 2015). Synthetic wheat genotypes are developed by crossing wild wheat (Aegilops tauschii) with durum wheat (T. durum Desf.) (Cossani and Reynolds, 2015). Tetraploid wheat (T. turgidum L.) is also identified as a useful genetic resource for wheat breeding possessing functional genes that surpass the early maturity effect caused by the early flowering allele Ppd-A1a found in T. turgidum L. (ssp. turgidum conv. pyramidale) (Nishimura et al., 2018). Wild emmer wheat is also considered a promising source of useful genes for improving stress resistance, grain protein quality and quantity, and micronutrient concentrations in domesticated wheat (Xie and Nevo, 2008; Merchuk-Ovnat et al., 2016). Wheat genotypes with drought and heat tolerance that incorporated genes from landraces and synthetic wheat have been developed for cultivation in arid and semi-arid environments to boost grain yield potential (Lopes et al., 2012; Cossani and Reynolds, 2015; Mondal et al., 2016; Pinto et al., 2017; Crespo-Herrera et al., 2018). Further, molecular, and physiological characterization of wheat genetic resources is useful to increase the probability of achieving cumulative gene action to improve yield gains (Ortiz et al., 2008; Reynolds et al., 2017).

\section{QUANTITATIVE TRAIT LOCI (QTLS) ASSOCIATED WITH AGRONOMIC AND PHYSIOLOGICAL TRAITS IN WHEAT}

QTL mapping of agronomic and physiological traits is important for marker-assisted breeding in wheat (Huang et al., 2003; Lozada et al., 2017; Li et al., 2018; Liu et al., 2018b). Agronomic and physiological traits are controlled by a number of QTL (Tables 3, 4). Several multiple QTLs linked to agronomic traits have also been identified such as QTLs QTn.ipk-5D, QTn.ipk-2D, $Q T n . i p k-3 B$, and $Q T n . i p k-1 B$ which are associated with productive tiller number (Huang et al., 2003). QTL QFlt.dms-2D, QFlt. dms-5B, QFlt.dms-2D, QFlt.dms-7A, and QFlt.dms-6B.2 are linked to days to flowering; whereas, QTLs QMat.dms-2D, QMat.dms-2D, QMat.dms-7A.2, and QMat.dms-4A.1 are associated with days to maturity (Perez-Lara et al., 2016). About 40 QTL's associated with kernel morphological traits such as kernel length, kernel width, kernel thickness, kernel length/width ratio, kernel length/thickness ratio, and kernel width/thickness ratio have been recently mapped in wheat (Chen et al., 2019). New QTLs linked to FLL, FLW, and FLA were recently identified and mapped in wheat (Liu et al., 2018a, Liu et al., 2018b). QTLs for root and root-related traits have also been mapped in wheat (Table 3) (Hamada et al., 2012; Bai et al., 2013). QTL's for root component traits were reported to be co-located with those controlling plant height, indicating that wheat genotypes possessing height reducing genes (i.e., Rht) may have reduced root growth under water-stressed environments (Bai et al., 2013). Further, QTLs controlling canopy temperature reportedly affects root system development (Ren et al., 2010). The identified QTLs can be transferred to new or well-adapted cultivars to improve yield in wheat (Zhang et al., 2018).

Maqsood et al. (2017) identified QTL linked to relative water content, cell wall membrane thermo-stability, and photosynthetic 
TABLE 3 | Key agronomic traits and their quantitative trait loci (QTLs) in wheat.

\begin{tabular}{|c|c|c|c|}
\hline Trait & QTL name & $\begin{array}{c}\text { Chromosome } \\
\text { location of } \\
\text { QTL }\end{array}$ & References \\
\hline \multirow{4}{*}{$\begin{array}{l}\text { Days to } \\
\text { flowering \& } \\
\text { maturity }\end{array}$} & QEps.dms-1B1 & $1 \mathrm{~B}$ & Kamran et al. (2013b) \\
\hline & QEps.dms-1B2 & $1 \mathrm{~B}$ & Kamran et al. (2013b) \\
\hline & QEps.dms-5B1 & $5 B$ & Kamran et al. (2013b) \\
\hline & $w P t-741686$ & $7 \mathrm{~A}$ & Ogbonnaya et al. (2017) \\
\hline \multirow{9}{*}{$\begin{array}{l}\text { Days to } \\
\text { flowering }\end{array}$} & QFlt.dms-4A1 & $4 \mathrm{~A}$ & Kamran et al. (2013b) \\
\hline & QEps.dms-1B1 & $1 \mathrm{~B}$ & Kamran et al. (2013b) \\
\hline & QEps.dms-5B1 & $5 B$ & Kamran et al. (2013b) \\
\hline & QFlt.dms-4A.1 & $4 \mathrm{~A}$ & Kamran et al. (2013b) \\
\hline & $V R N-A 1$ & $5 \mathrm{~A}$ & Ogbonnaya et al. (2017) \\
\hline & wPt-2822 & $6 \mathrm{~A}$ & Ogbonnaya et al. (2017) \\
\hline & VRN-B1 & $5 B$ & Ogbonnaya et al. (2017) \\
\hline & VRN-D1 & $5 \mathrm{D}$ & Ogbonnaya et al. (2017) \\
\hline & $w P t-741686$ & $7 \mathrm{~A}$ & Ogbonnaya et al. (2017) \\
\hline \multirow[t]{9}{*}{ Plant height } & QPH.cgb-1B.1 & $1 \mathrm{~B}$ & Wu et al. (2012) \\
\hline & QPH.cgb-2D. 1 & $2 \mathrm{D}$ & Wu et al. (2012) \\
\hline & QPH.cgb-4D & $4 \mathrm{D}$ & Wu et al. (2012) \\
\hline & QPH.cgb-6B.6 & $6 \mathrm{~B}$ & Wu et al. (2012) \\
\hline & Rht24 & $6 \mathrm{~A}$ & Würschum et al. (2017) \\
\hline & qRht.3A & $3 A$ & Würschum et al. (2017) \\
\hline & qRht.2D & $2 \mathrm{D}$ & Würschum et al. (2017) \\
\hline & Ppd-D1 & $2 \mathrm{D}$ & Würschum et al. (2017) \\
\hline & wPt-1038 & $5 \mathrm{~A}$ & Ogbonnaya et al. (2017) \\
\hline \multirow[t]{2}{*}{ Harvest index } & $q H I-2 B$ & $2 \mathrm{~B}$ & Ehdaie et al. (2016) \\
\hline & $q H I-2 D$ & $2 \mathrm{D}$ & Ehdaie et al. (2016) \\
\hline \multirow[t]{12}{*}{ Biomass } & qPBio-7D & $7 \mathrm{D}$ & Ehdaie et al. (2016) \\
\hline & qPBio-2D & $2 \mathrm{D}$ & Ehdaie et al. (2016) \\
\hline & qPBio-3A & $3 A$ & Ehdaie et al. (2016) \\
\hline & qPBio-6B2 & $6 \mathrm{~B}$ & Ehdaie et al. (2016) \\
\hline & qSBio-2D & $2 \mathrm{D}$ & Ehdaie et al. (2016) \\
\hline & qSBio-6B & $6 \mathrm{~B}$ & Ehdaie et al. (2016) \\
\hline & qSBio-2A & $2 \mathrm{~A}$ & Ehdaie et al. (2016) \\
\hline & qSBio-7D & 7D & Ehdaie et al. (2016) \\
\hline & qPBio-4A & $4 \mathrm{~A}$ & Ehdaie et al. (2016) \\
\hline & qPBio-6B1 & $6 \mathrm{~B}$ & Ehdaie et al. (2016) \\
\hline & qSBio-1B & $1 \mathrm{~B}$ & Ehdaie et al. (2016) \\
\hline & qPBio-1B & $1 \mathrm{~B}$ & Ehdaie et al. (2016) \\
\hline \multirow{21}{*}{$\begin{array}{l}\text { Thousand } \\
\text { grain weight }\end{array}$} & QTGW.cgb-2D.2 & $2 \mathrm{D}$ & Wu et al. (2012) \\
\hline & QTGW.cgb-3A.4 & $3 A$ & Wu et al. (2012) \\
\hline & IWB36400 & $2 \mathrm{~A}$ & Sukumaran et al. (2018) \\
\hline & IWB2414 & $2 \mathrm{~B}$ & Sukumaran et al. (2018) \\
\hline & IWB42660 & $2 \mathrm{~B}$ & Sukumaran et al. (2018) \\
\hline & IWB9110 & $1 \mathrm{~B}$ & Sukumaran et al. (2018) \\
\hline & IWB23810 & $3 \mathrm{D}$ & Sukumaran et al. (2018) \\
\hline & IWB8975 & $5 \mathrm{~A}$ & Sukumaran et al. (2018) \\
\hline & IWB65783 & $6 \mathrm{~A}$ & Sukumaran et al. (2018) \\
\hline & IWB52005 & $6 \mathrm{~B}$ & Sukumaran et al. (2018) \\
\hline & IWB18267 & 7D & Sukumaran et al. (2018) \\
\hline & IWB15280 & $7 \mathrm{D}$ & Sukumaran et al. (2018) \\
\hline & D3956560 & $2 \mathrm{~A}$ & Würschum et al. (2018) \\
\hline & D1296988 & $3 \mathrm{D}$ & Würschum et al. (2018) \\
\hline & Rht-D1 & $4 \mathrm{D}$ & Würschum et al. (2018) \\
\hline & $R h t-B 1$ & $4 \mathrm{~B}$ & Würschum et al. (2018) \\
\hline & wPt-2315 & $1 \mathrm{~B}$ & Ogbonnaya et al. (2017) \\
\hline & $w P t-0153$ & $2 \mathrm{D}$ & Ogbonnaya et al. (2017) \\
\hline & $w P t-733777$ & $1 \mathrm{~A}$ & Ogbonnaya et al. (2017) \\
\hline & wPt-742925 & $5 \mathrm{~A}$ & Ogbonnaya et al. (2017) \\
\hline & $w P t-4229$ & $6 \mathrm{~A}$ & Ogbonnaya et al. (2017) \\
\hline
\end{tabular}

TABLE 3 | Continued

\begin{tabular}{|c|c|c|c|}
\hline Trait & QTL name & $\begin{array}{c}\text { Chromosome } \\
\text { location of } \\
\text { QTL }\end{array}$ & References \\
\hline \multirow{2}{*}{$\begin{array}{l}\text { Grain weight } \\
\text { per spike }\end{array}$} & wPt-6709 & $1 \mathrm{~A}$ & Ogbonnaya et al. (2017) \\
\hline & $w P t-6502$ & $4 \mathrm{~A}$ & Ogbonnaya et al. (2017) \\
\hline \multirow{11}{*}{$\begin{array}{l}\text { Number of } \\
\text { grains per } \\
\text { spike }\end{array}$} & QNGS.cgb-2B & 2B & Wu et al. (2012) \\
\hline & QNGS.cgb-7A & $7 \mathrm{~A}$ & Wu et al. (2012) \\
\hline & S3222159 & $2 \mathrm{~A}$ & Würschum et al. (2018) \\
\hline & S1290099 & $2 \mathrm{~A}$ & Würschum et al. (2018) \\
\hline & $D 1280633$ & $7 \mathrm{~A}$ & Würschum et al. (2018) \\
\hline & D1091178 & $4 \mathrm{~A}$ & Würschum et al. (2018) \\
\hline & D1056474 & $3 B$ & Würschum et al. (2018) \\
\hline & Rht-D1 & 4D & Würschum et al. (2018) \\
\hline & $w P t-730427$ & $2 \mathrm{D}$ & Ogbonnaya et al. (2017) \\
\hline & wPt-731291 & $7 \mathrm{~A}$ & Ogbonnaya et al. (2017) \\
\hline & qNGS-2B & $2 \mathrm{~B}$ & Ehdaie et al. (2016) \\
\hline \multirow[t]{10}{*}{ Spike length } & $\begin{array}{l}\text { Xbcd1150- } \\
\text { Xbarc61 }\end{array}$ & $1 \mathrm{~A}$ & Yu et al. (2014) \\
\hline & $\begin{array}{l}\text { Xmwg912- } \\
\text { Xbarc80 }\end{array}$ & $1 \mathrm{~B}$ & Yu et al. (2014) \\
\hline & D3027644 & $2 \mathrm{~A}$ & Würschum et al. (2018) \\
\hline & $\begin{array}{l}\text { S1006957 } \\
\text { (Rht24) }\end{array}$ & $6 \mathrm{~A}$ & Würschum et al. (2018) \\
\hline & $D 1128060$ & 3B & Würschum et al. (2018) \\
\hline & D1109894 & $6 \mathrm{~B}$ & Würschum et al. (2018) \\
\hline & D3064960 & $6 \mathrm{~B}$ & Würschum et al. (2018) \\
\hline & D1109894 & $6 \mathrm{~B}$ & Würschum et al. (2018) \\
\hline & $P p d-D 1$ & $2 \mathrm{D}$ & Würschum et al. (2018) \\
\hline & wPt-2872 & $1 \mathrm{~A}$ & Ogbonnaya et al. (2017) \\
\hline \multirow[t]{6}{*}{ Spike fertility } & QPFSS.cgb-5A.2 & $5 \mathrm{~A}$ & Wu et al. (2012) \\
\hline & QPFSS.cgb-7A & $7 \mathrm{~A}$ & Wu et al. (2012) \\
\hline & Rht-B1 & 4B & Würschum et al. (2018) \\
\hline & Rht-D1 & $4 \mathrm{D}$ & Würschum et al. (2018) \\
\hline & S1019498 & $2 \mathrm{~A}$ & Würschum et al. (2018) \\
\hline & D1253047 & $4 \mathrm{~A}$ & Würschum et al. (2018) \\
\hline Spikelets & D1108041 & $2 \mathrm{~A}$ & Würschum et al. (2018) \\
\hline
\end{tabular}

number per

spike

\begin{tabular}{|c|c|}
\hline & D1128642 \\
\hline & D1082846 \\
\hline & S2255090 \\
\hline & Ppd-D1 \\
\hline & D1208470 \\
\hline & $w P t-732556$ \\
\hline & $w P t-5787$ \\
\hline & wPt-4295 \\
\hline & wPt-5742 \\
\hline & wPt-2883 \\
\hline & wPt-4315 \\
\hline & $w P t-731810$ \\
\hline Spike & D1221700 \\
\hline compactness & \\
\hline & S1089640 \\
\hline & D1109152 \\
\hline & (Rht24) \\
\hline & D2254379 \\
\hline & D1100166 \\
\hline & S997641 \\
\hline & S2255090 \\
\hline $\begin{array}{l}\text { Number of } \\
\text { productive tillers }\end{array}$ & Qltn.sicau-2B \\
\hline
\end{tabular}

Würschum et al. (2018) Würschum et al. (2018) Würschum et al. (2018) Würschum et al. (2018) Würschum et al. (2018) Ogbonnaya et al. (2017) Ogbonnaya et al. (2017) Ogbonnaya et al. (2017) Ogbonnaya et al. (2017) Ogbonnaya et al. (2017) Ogbonnaya et al. (2017) Würschum et al. (2018)

Würschum et al. (2018) Würschum et al. (2018) Würschum et al. (2018) Würschum et al. (2018) Würschum et al. (2018) Wang et al. (2016) Ogbonnaya et al. (2017)

Würschum et al. (2018) 
TABLE 3 | Continued

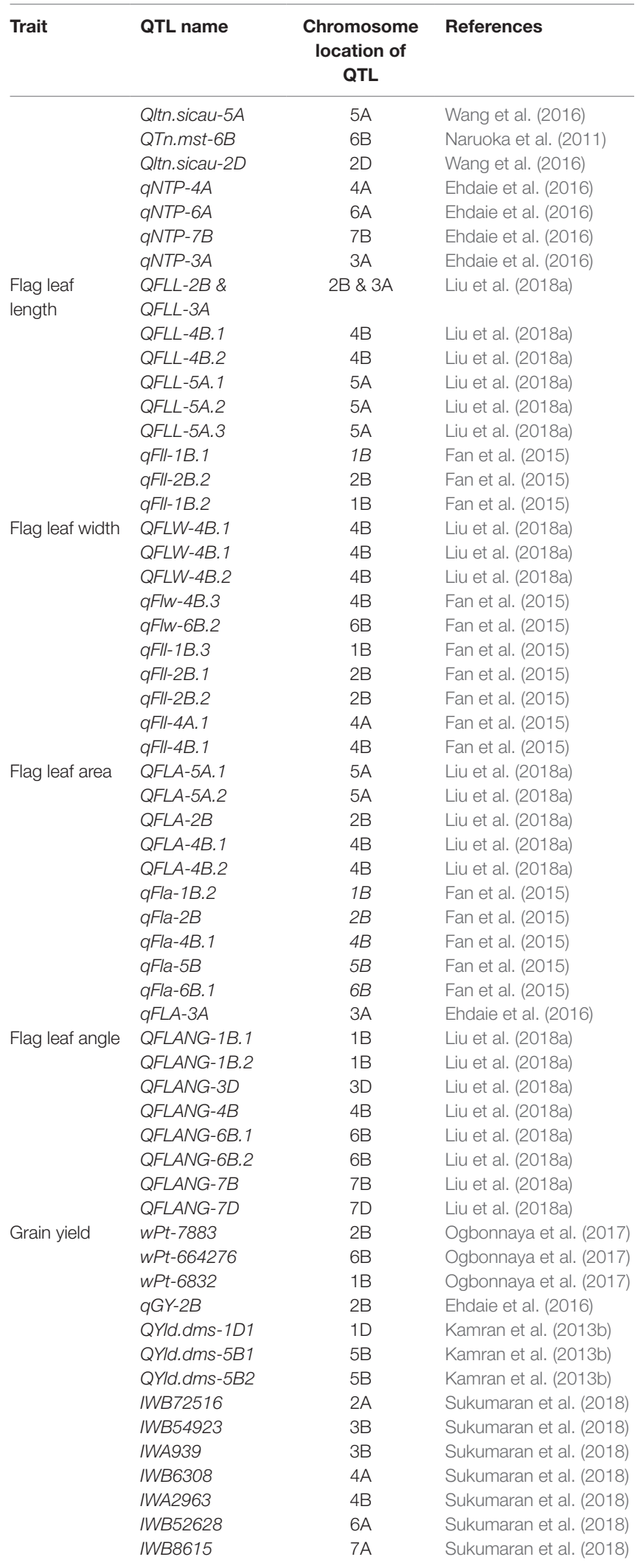

TABLE 3 | Continued

\begin{tabular}{|c|c|c|c|}
\hline Trait & QTL name & $\begin{array}{c}\text { Chromosome } \\
\text { location of } \\
\text { QTL }\end{array}$ & References \\
\hline \multirow{2}{*}{$\begin{array}{l}\text { Root } \\
\text { elongation } \\
\text { rate }\end{array}$} & qER-1 & $5 \mathrm{D}$ & Hamada et al. (2012) \\
\hline & $q E R-2$ & $7 \mathrm{D}$ & Hamada et al. (2012) \\
\hline \multirow{15}{*}{$\begin{array}{l}\text { Maximum } \\
\text { root length }\end{array}$} & $q M R L-2 B$ & $2 \mathrm{~B}$ & Ren et al. (2012) \\
\hline & qMRL-7B1 & $7 \mathrm{~B}$ & Ren et al. (2012) \\
\hline & QMrl-2A.1 & $2 \mathrm{~A}$ & Kabir et al. (2015) \\
\hline & QMrl-2A.2 & $2 \mathrm{~A}$ & Kabir et al. (2015) \\
\hline & QMrl-2A.3 & $2 \mathrm{~A}$ & Kabir et al. (2015) \\
\hline & QMrl-4D.1 & $4 \mathrm{D}$ & Kabir et al. (2015) \\
\hline & QMrl-4D.2 & $4 \mathrm{D}$ & Kabir et al. (2015) \\
\hline & QMrl-5A.1 & $5 A$ & Kabir et al. (2015) \\
\hline & QMrl-5A.2 & $5 \mathrm{~A}$ & Kabir et al. (2015) \\
\hline & QMrl-6A & $6 A$ & Kabir et al. (2015) \\
\hline & QMrl-7B.1 & $7 \mathrm{~B}$ & Kabir et al. (2015) \\
\hline & QMrl-7B.2 & $7 \mathrm{~B}$ & Kabir et al. (2015) \\
\hline & QMrl-3B.1 & $3 B$ & Kabir et al. (2015) \\
\hline & QMrl-3B.2 & $3 B$ & Kabir et al. (2015) \\
\hline & QMrl-5B & $5 B$ & Kabir et al. (2015) \\
\hline \multirow{7}{*}{$\begin{array}{l}\text { Primary root } \\
\text { length }\end{array}$} & $q P R L-2 B 1$ & $2 \mathrm{~B}$ & Ren et al. (2012) \\
\hline & $q P R L-2 B 2$ & $2 \mathrm{~B}$ & Ren et al. (2012) \\
\hline & $q P R L-7 B$ & $7 \mathrm{~B}$ & Ren et al. (2012) \\
\hline & QMrl-2A.1 & $2 \mathrm{~A}$ & Kabir et al. (2015) \\
\hline & QMrl-2A.2 & $2 \mathrm{~A}$ & Kabir et al. (2015) \\
\hline & QMrl-2A.3 & $2 \mathrm{~A}$ & Kabir et al. (2015) \\
\hline & QMrl-4D.1 & $4 \mathrm{D}$ & Kabir et al. (2015) \\
\hline \multirow{6}{*}{$\begin{array}{l}\text { Lateral root } \\
\text { length }\end{array}$} & $q L R L-1 A$ & $1 \mathrm{~A}$ & Ren et al. (2012) \\
\hline & $q L R L-2 B$ & $2 \mathrm{~B}$ & Ren et al. (2012) \\
\hline & $q L R L-4 B$ & $4 \mathrm{~B}$ & Ren et al. (2012) \\
\hline & $q L R L-6 A$ & $6 A$ & Ren et al. (2012) \\
\hline & $q L R L-6 B 1$ & $6 \mathrm{~B}$ & Ren et al. (2012) \\
\hline & $q L R L-6 B 2$ & $6 B$ & Ren et al. (2012) \\
\hline \multirow[t]{15}{*}{ Total root length } & qTRL-2B & $2 \mathrm{~B}$ & Ren et al. (2012) \\
\hline & $q T R L-4 B$ & $4 \mathrm{~B}$ & Ren et al. (2012) \\
\hline & $q T R L-6 A$ & $6 \mathrm{~A}$ & Ren et al. (2012) \\
\hline & $q T R L-6 B$ & $6 \mathrm{~B}$ & Ren et al. (2012) \\
\hline & qTRL-6D & $6 \mathrm{D}$ & Ren et al. (2012) \\
\hline & QTrl-2A.1 & $2 \mathrm{~A}$ & Kabir et al. (2015) \\
\hline & QTrI-2A.2 & $2 \mathrm{~A}$ & Kabir et al. (2015) \\
\hline & QTrl-2B & $2 \mathrm{~B}$ & Kabir et al. (2015) \\
\hline & QTrl-3A.1 & $3 A$ & Kabir et al. (2015) \\
\hline & QTrl-3A.2 & $3 A$ & Kabir et al. (2015) \\
\hline & QTrI-3A.3 & $3 A$ & Kabir et al. (2015) \\
\hline & QTrl-3A.4 & $3 A$ & Kabir et al. (2015) \\
\hline & $Q T r 1-4 D$ & $3 A$ & Kabir et al. (2015) \\
\hline & QTrl-5A.1 & $5 A$ & Kabir et al. (2015) \\
\hline & QTrl-5A.2 & $5 A$ & Kabir et al. (2015) \\
\hline \multirow{5}{*}{$\begin{array}{l}\text { Total root } \\
\text { length }\end{array}$} & $Q T r 1-2 B$ & $2 \mathrm{~B}$ & Kabir et al. (2015) \\
\hline & QTrI-3B & $3 B$ & Kabir et al. (2015) \\
\hline & QTrl-4A & $4 \mathrm{~A}$ & Kabir et al. (2015) \\
\hline & $Q T r 1-4 D$ & $4 \mathrm{D}$ & Kabir et al. (2015) \\
\hline & $Q T r 1-6 D$ & $6 D$ & Kabir et al. (2015) \\
\hline $\begin{array}{l}\text { Seminal root } \\
\text { angle }\end{array}$ & $q S R A-6 A$ & $6 A$ & Alahmad et al. (2019) \\
\hline $\begin{array}{l}\text { Root angle, } \\
\text { length, number }\end{array}$ & Root_MQTL_18 & $2 \mathrm{~A}$ & $\begin{array}{l}\text { Soriano and Alvaro } \\
\text { (2019) }\end{array}$ \\
\hline
\end{tabular}

(Continued)

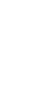


TABLE 3 | Continued

\begin{tabular}{|c|c|c|c|}
\hline Trait & QTL name & $\begin{array}{c}\text { Chromosome } \\
\text { location of } \\
\text { QTL }\end{array}$ & References \\
\hline & Root_MQTL_2 & $1 \mathrm{~A}$ & $\begin{array}{l}\text { Soriano and Alvaro } \\
\text { (2019) }\end{array}$ \\
\hline & Root_MQTL_8 & $1 \mathrm{~B}$ & $\begin{array}{l}\text { Soriano and Alvaro } \\
\text { (2019) }\end{array}$ \\
\hline & Root_MQTL_22 & $2 \mathrm{~B}$ & $\begin{array}{l}\text { Soriano and Alvaro } \\
\text { (2019) }\end{array}$ \\
\hline & Root_MQTL_25 & $2 \mathrm{~B}$ & $\begin{array}{l}\text { Soriano and Alvaro } \\
\text { (2019) }\end{array}$ \\
\hline & Root_MQTL_40 & $3 B$ & $\begin{array}{l}\text { Soriano and Alvaro } \\
\text { (2019) }\end{array}$ \\
\hline & Root_MQTL_52 & $4 \mathrm{~B}$ & $\begin{array}{l}\text { Soriano and Alvaro } \\
\text { (2019) }\end{array}$ \\
\hline & Root_MQTL_69 & $6 A$ & $\begin{array}{l}\text { Soriano and Alvaro } \\
\text { (2019) }\end{array}$ \\
\hline $\begin{array}{l}\text { Root: shoot } \\
\text { ratio }\end{array}$ & Root_MQTL_18 & $2 \mathrm{~A}$ & $\begin{array}{l}\text { Soriano and Alvaro } \\
\text { (2019) }\end{array}$ \\
\hline \multirow{4}{*}{$\begin{array}{l}\text { Shallow root } \\
\text { weight }\end{array}$} & qSRW-3A & $3 A$ & Ehdaie et al. (2016) \\
\hline & $q S R W-2 A$ & $2 \mathrm{~A}$ & Ehdaie et al. (2016) \\
\hline & $q S R W-2 D$ & $2 \mathrm{D}$ & Ehdaie et al. (2016) \\
\hline & $q S R W-4 A$ & $4 \mathrm{~A}$ & Ehdaie et al. (2016) \\
\hline \multirow{6}{*}{$\begin{array}{l}\text { Deep root } \\
\text { weight }\end{array}$} & $q D R W-1 B$ & $1 \mathrm{~B}$ & Ehdaie et al. (2016) \\
\hline & $q D R W-4 B 1$ & $4 \mathrm{~B}$ & Ehdaie et al. (2016) \\
\hline & $q D R W-4 B 2$ & $4 \mathrm{~B}$ & Ehdaie et al. (2016) \\
\hline & $q D R W-2 D$ & $2 \mathrm{D}$ & Ehdaie et al. (2016) \\
\hline & $9 D R W-3 A$ & $3 A$ & Ehdaie et al. (2016) \\
\hline & $q D R W-4 A$ & $4 \mathrm{~A}$ & Ehdaie et al. (2016) \\
\hline Root biomass & qRBio-3A & $3 A$ & Ehdaie et al. (2016) \\
\hline
\end{tabular}

rate. Christopher et al. (2018) identified several QTLs associated with the stay-green trait in wheat. QTLs for photosynthetic rate were identified on chromosomes 2A and 7D (llyas et al., 2014). In certain instances, genetic regions linked to physiological traits (e.g. stay-green) were co-located with QTL for yield-related traits yield (Acuna-Galindo et al., 2014). Genomic regions have also been reported for grain yield, thousand kernel weight, biomass, and days to heading which suggested that a group of linked and (or) co-located QTL affected phenological and yield-related traits (Tahmasebi et al., 2016). QTL involved in days to heading and thousand grain weight suggested that early maturity would favour the post-anthesis grain-filling periods and increased grain size and grain yield (Tahmasebi et al., 2016). QTL for chlorophyll content, WUE, photosynthetic rate, and internal $\mathrm{CO}_{2}$ concentration were co-located with QTL for grain yield and/or yield components (Xu et al., 2017). QTL which simultaneously control flag leaf traits and yield related traits have also been identified on chromosomes $1 \mathrm{~B}, 2 \mathrm{D}, 4 \mathrm{~A}$, 4D, 4B, 5A, 5B, 6B, 6D, and 7D in wheat (Fan et al., 2015; Wu et al., 2016). Such pleiotropic effects are useful to understand relationships among QTLs and pyramiding favourable alleles in different genetic loci (Hai et al., 2008). Marker-assisted recurrent selection involving pyramiding of important QTL can improve grain yield potential in wheat (Gahlaut et al., 2017). Generally, QTL mapped for physiological traits are limited in wheat, only few identified for chlorophyll content, normalized difference in vegetation index (NDVI), and CT (Table 4). Though heritability of physiogical traits
TABLE 4 | Quantitative trait loci (QTLs) of some physiological traits in wheat.

\begin{tabular}{|c|c|c|c|}
\hline Trait & QTL name & $\begin{array}{c}\text { Chromosome } \\
\text { location of } \\
\text { QTL }\end{array}$ & References \\
\hline \multirow{3}{*}{$\begin{array}{l}\text { Canopy } \\
\text { temperature }\end{array}$} & $4 A-w m c 048 d$ & $4 \mathrm{~A}$ & Lopes et al. (2013) \\
\hline & $6 A-g w m 617 b$ & $7 \mathrm{D}$ & Lopes et al. (2013) \\
\hline & C29P13 & $7 \mathrm{D}$ & Lopes et al. (2013) \\
\hline \multirow[t]{10}{*}{ Stay-green } & QSG.qgw-3B.1 & $3 \mathrm{~A}$ & Christopher et al. (2018) \\
\hline & QSG.qgw-7B & $7 \mathrm{~B}$ & Christopher et al. (2018) \\
\hline & QSG.qgw-1B & $1 \mathrm{~B}$ & Christopher et al. (2018) \\
\hline & QSG.qgw-2A & $2 \mathrm{~A}$ & Christopher et al. (2018) \\
\hline & qSG.qgw-3B.2 & $3 B$ & Christopher et al. (2018) \\
\hline & QSG.qgw-4A.1 & $4 \mathrm{~A}$ & Christopher et al. (2018) \\
\hline & QSG.qgw-4A.2 & $4 \mathrm{~A}$ & Christopher et al. (2018) \\
\hline & QSG.qgw-4B & $4 \mathrm{~B}$ & Christopher et al. (2018) \\
\hline & QSG.qgw-4D & $4 \mathrm{D}$ & Christopher et al. (2018) \\
\hline & QSG.qgw-5B & $5 \mathrm{~B}$ & Christopher et al. (2018) \\
\hline \multirow{4}{*}{$\begin{array}{l}\text { Chlorophyll } \\
\text { content }\end{array}$} & QCh/c.cgb-7A & $7 \mathrm{~A}$ & Yang et al. (2007a) \\
\hline & QCh/c.cgb-5A-1 & $5 \mathrm{~A}$ & Yang et al. (2007a) \\
\hline & QCh/c.cgb-1A & $1 \mathrm{~A}$ & Yang et al. (2007a) \\
\hline & QCh/c.cgb-5A-2 & $5 \mathrm{~A}$ & Yang et al. (2007a) \\
\hline \multirow{5}{*}{$\begin{array}{l}\text { Photosynthetic } \\
\text { capacity }\end{array}$} & QFv/Fm.cgb-3B-1 & $3 B$ & Yang et al. (2007a) \\
\hline & QFv/Fm.cgb-3B-2 & $3 B$ & Yang et al. (2007a) \\
\hline & QFv/Fm.cgb-6A & $6 \mathrm{~A}$ & Yang et al. (2007a) \\
\hline & QFv/Fm.cgb-7D-1 & $7 \mathrm{D}$ & Yang et al. (2007a) \\
\hline & QFv/Fm.cgb-1B & $1 B$ & Yang et al. (2007a) \\
\hline \multirow{10}{*}{$\begin{array}{l}\text { Water-soluble } \\
\text { carbohydrates }\end{array}$} & QSwscf.cgb-1A.1 & $1 \mathrm{~A}$ & Yang et al. (2007b) \\
\hline & QSwscf.cgb-4B.1 & $4 \mathrm{~B}$ & Yang et al. (2007b) \\
\hline & QSwscf.cgb-1D.1 & $1 \mathrm{D}$ & Yang et al. (2007b) \\
\hline & QSwscg.cgb-4A & $4 \mathrm{~A}$ & Yang et al. (2007b) \\
\hline & QSwscm.cgb-1A.1 & $1 \mathrm{~A}$ & Yang et al. (2007b) \\
\hline & QSwscf.cgb-2D.1 & $2 \mathrm{D}$ & Yang et al. (2007b) \\
\hline & QSwscf.cgb-2D.2 & $2 \mathrm{D}$ & Yang et al. (2007b) \\
\hline & QSwscf.cgb-7B.1 & $7 \mathrm{~B}$ & Yang et al. (2007b) \\
\hline & QSwscf.cgb-7D & $7 \mathrm{D}$ & Yang et al. (2007b) \\
\hline & QSwscm.cgb-6B.1 & $6 \mathrm{~B}$ & Yang et al. (2007b) \\
\hline \multirow{15}{*}{$\begin{array}{l}\text { Normalized } \\
\text { vegetation } \\
\text { index }\end{array}$} & QNDVI-A.caas-4AL & $4 \mathrm{~A}$ & Gao et al. (2015) \\
\hline & QNDVI-A.caas-3AL & $3 \mathrm{~A}$ & Gao et al. (2015) \\
\hline & QNDVI-A.caas-1BS & $1 \mathrm{~B}$ & Gao et al. (2015) \\
\hline & QNDVI-A.caas-5BL & $5 B$ & Gao et al. (2015) \\
\hline & QNDVI-A.caas-5BS.1 & $5 B$ & Gao et al. (2015) \\
\hline & QNDVI-A.caas-4BS & $4 \mathrm{~B}$ & Gao et al. (2015) \\
\hline & QNDVI-A.caas-4DS & $4 \mathrm{D}$ & Gao et al. (2015) \\
\hline & QNDVI-A.caas-5AL & $5 \mathrm{~A}$ & Gao et al. (2015) \\
\hline & QNDVI-A.caas-3AL & $3 A$ & Gao et al. (2015) \\
\hline & QNDVI-10.caas-2DS & $2 \mathrm{D}$ & Gao et al. (2015) \\
\hline & QNDVI-10.caas-5AL & $5 \mathrm{~A}$ & Gao et al. (2015) \\
\hline & QNDVI-10.caas-4BS & $4 \mathrm{~B}$ & Gao et al. (2015) \\
\hline & QNDVI-10.caas-5BL & $5 B$ & Gao et al. (2015) \\
\hline & QNDVI-10.caas-6BL & $6 \mathrm{~B}$ & Gao et al. (2015) \\
\hline & QNDVI-10.caas-4DS & $4 \mathrm{D}$ & Gao et al. (2015) \\
\hline
\end{tabular}

is relatively low (Chen et al., 2012; Ogbonnaya et al., 2017), their incorporation in breeding programmes may be useful for cultivar development (Lopes et al., 2012). Therefore, to accelerate breeding aimed at improving grain yield genetic gains in wheat, it is important to dissect genomic regions influencing physiological traits and design associated markers for strategic breeding. 
In conclusion, genetic improvement can be achieved by either direct selection for primary traits such as grain yield or indirectly through selection of secondary traits related to higher grain yield potential. Breeding high-yielding genotypes incorporating yield-promoting agronomic and physiological traits has accelerated yield gains in wheat. As a result, further grain yield improvement will likely be achieved through in/direct selection targeting yield-related agronomic and physiological attributes. Furthermore, QTL associated with agronomic and physiological traits linked to grain yield are useful for marker-assisted selection of high-performing wheat genotypes.

\section{REFERENCES}

Abdolshahi, R., Nazari, M., Safarian, A., Sadathossini, T. S., Salarpour, M., and Amiri, H. (2015). Integrated selection criteria for drought tolerance in wheat (Triticum aestivum L.) breeding programs using discriminant analysis. Field Crops Res. 174, 20-29. doi: 10.1016/j.fcr.2015.01.009

Acuna-Galindo, M. A., Mason, R. E., Subrahmanyam, N. K., and Hays, D. (2014). Meta-analysis of wheat QTL regions associated with adaptation to drought and heat stress. Crop Sci. 55, 477-492. doi: 10.2135/cropsci2013.11.0793

Addison, C. K., Mason, R. E., Brown-Guedira, G., Guedira, M., Hao, Y., Miller, R. G., et al. (2016). QTL and major genes influencing grain yield potential in soft red winter wheat adapted to the southern United States. Euphytica. 209, 665-677. doi: 10.1007/s10681-016-1650-1.

Aisawi, K. A. B., Reynolds, M. P., Singh, R. P., and Foulkes, M. J. (2015). The physiological basis of the genetic progress in yield potential of CIMMYT spring wheat cultivars from 1966 to 2009. Crop Sci. 55, 1749-1764. doi: 10.2135/ cropsci2014.09.0601

Alahmad, S., El Hassouni, K., Bassi, F. M., Dinglasan, E., Youssef, C., Quarry, G., et al. (2019). A major root architecture QTL responding to water limitation in durum wheat. Front. Plant Sci. 10, 436. doi: 10.3389/fpls.2019.00436.

Alonso, M. P., Mirabella, N. E., and Panelo, J. S. (2018). Selection for high spike fertility index increases genetic progress in grain yield and stability in bread wheat. Euphytica 214, 112. doi: 10.1007/s10681-018-2193-4

Acreche, M. M., Briceno-Felix, G., Sanchez, J., and Slafer, G. A. (2008). Physiological basesof genetic gains in Mediterranean bread wheat yield in Spain. Eur. J. Agron. 28, 162-170. doi: 10.1016/j.eja.2007.07.001

Bai, C., Liang, Y., and Hawkesford, M. J. (2013). Identification of QTLs associated with seedling root traits and their correlation with plant height in wheat. J. Exp. Bot. 64, 1745-1753. doi: 10.1093/jxb/ert041

Balota, M., Green, A. J., Griffey, C. A., Pitman, R., and Thomason, W. (2017). Genetic gains for physiological traits associated with yield in soft red winter wheat in the Eastern United States from 1919 to 2009. Eur. J. Agron. 84, 76-83. doi: 10.1016/j.eja.2016.11.008

Battenfield, S. D., Klatt, A. R., and Raun, W. R. (2013). Genetic Yield Potential Improvement of Semidwarf Winter Wheat in the Great Plains. Crop Sci. 53, 946-955. doi: 10.2135/cropsci2012.03.0158

Beche, E., Benin, D., Da Silva, C. L., Munaro, L. B., and Marchese, J. A. (2014). Genetic gain in yield and changes associated with physiological traits in Brazilian wheat during the 20th century. Eur. J. Agron. 61, 49-59. doi: 10.1016/j. eja.2014.08.005

Berry, P. M., Kendall, S., and Rutterford, Z. (2015). Historical analysis of the effects of breeding on the height of winter wheat (Triticum aestivum) and consequences for lodging. Euphytica 203, 375. doi: 10.1007/s10681-014-1286-y

Brisson, N., Gate, P., Gouache, D., Charmet, G., Oury, F., and Huard, F. (2010). Why are wheat yields stagnating in Europe? A Compr. Data Anal. Fr Field Crops Res. 119, 201-212. doi: 10.1016/j.fcr.2010.07.012

Bornhofen, E., Todeschini, M. H., Stoco, M. G., Madureira, A., Marchioro, V. S., Storck, L., et al (2018). Wheat yield improvements in Brazil: roles of genetics and environment. Crop Sci. 58, 1082-1093. doi: 10.2135/cropsci2017.06.0358

Bustos, D. V., Hasan, A. K., Reynolds, M. P., and Calderini, D. F. (2013). Combining high grain number and weight through a DH-population to improve grain

\section{AUTHOR CONTRIBUTIONS}

All authors listed have made substantial, direct and intellectual contribution to the work, and approved it for publication.

\section{ACKNOWLEDGMENTS}

National Research Foundation (NRF) of South Africa, University of KwaZulu-Natal, and the Limpopo Department of Agriculture and Rural Development are sincerely acknowledged for the allround support of the study.

yield potentialof wheat in high-yielding environments. Field Crops Res. 145 , 106-115. doi: 10.1016/j.fcr.2013.01.015

Calderini, D. F., and Reynolds, M. P. (2000). Changes in grain weight as a consequence of de-graining treatments at pre- and post-anthesis in synthetic hexaploid lines of wheat (Triticum durum $\times$ T. Funct. Plant Biol. 27, 183-191. doi: 10.1071/PP99066

Chairi, F., Vergara-Diaz, O., Vatter, T., Aparicio, N., Nieto-Taladriz, M. T., Kefauver, S. C., et al (2018). Post-green revolution genetic advance in durum wheat: The case of Spain. Field Crops Res. 228, 158-169. doi: 10.1016/j.fcr.2018.09.003

Chen, X., Min, D., Yasir, T. A., and Hu, Y. G. (2012). Evaluation of 14 morphological, yield-related and physiological traits as indicators of drought tolerance in Chinese winter bread wheat revealed by analysis of the membership function value of drought tolerance (MFVD). Field Crops Res. 137, 195-201. doi: 10.1016/j.fcr.2012.09.008

Chen, S., Gao, R., Wang, H., Wen M., Xiao, J., Bian, N., et al. (2015). Characterization of a novel reduced height gene (Rht23) regulating panicle morphology and plant architecture in bread wheat. Euphytica 203, 583. doi: 10.1007/s10681-014-1275-1.

Chen, H., Moakhar, N. P., Iqbal, M., Pozniak, C., Hucl, P., and Spaner, D. (2016). Genetic variation for flowering time and height reducing genes and important traits in western Canadian spring wheat. Euphytica 208, 377-390. doi: 10.1007/ s10681-015-1615-9

Chen, L., Yang, Y., Cui, C., Lu, S., Lu, Q., Du, Y., et al. (2018a). Effects of Vrn-B1 and Ppd-D1 on developmental and agronomic traits in Rht5 dwarf plants of bread wheat. Field Crops Res. 219, 24-32. doi: 10.1016/j.fcr.2018.01.022

Chen, L., Du, Y., Lu, Q., Chen, H., Meng, R., Cui, C., et al. (2018b). The photoperiodinsensitive allele Ppd-D1a promotes earlier flowering in Rht12 dwarf plants of bread wheat. Front. Plant Sci. 9, 1312. doi: 10.3389/fpls.2018.01312

Chen, W., Sun, D., Yan, X., Li, R., Wang, S., Shi, Y., et al. (2019). QTL analysis of wheat kernel traits, and genetic effects of qKW-6A on kernel width. Euphytica 215, 11. doi: 10.1007/s10681-018-2333-x

Chen, X., and Hao, M. D. (2015). Low contribution of photosynthesis and wateruse efficiency to improvement of grain yield in Chinese wheat. Photosynthetica 53, 519-526. doi: 10.1007/s11099-015-0147-9

Christopher, M., Chenu, K., Jennings, R., Fletcher, S., Butler, D., Borrell, A., et al (2018). QTL for stay-green traits in wheat in well-watered and water-limited environments. Field Crops Res. 17, 32-44. doi: 10.1016/j.fcr.2017.11.003

Cossani, C. M., and Reynolds, M. P. (2012). Physiological traits for improving heat tolerance in wheat. Plant Physiol. 160, 1710-1718. doi: 10.1104/pp.112.207753

Cossani, C. M., and Reynolds, M. P. (2015). Heat stress adaptation in elite lines derived from synthetic hexaploid wheat. Crop Sci. 55, 2719-2735. doi: 10.2135/ cropsci2015.02.0092

Crespo-Herrera, L. A., Crossa, J., Huerta-Espino, J., Vargas, M., Mondal, S., Velu, G., et al. (2018). Genetic gains for grain yield in CIMMYT's semi-arid wheat yield trials grown in suboptimal environments. Crop Sci. 58, 1890-1189. doi: 10.2135/cropsci2018.01.0017

Daoura, B. G., Chen, L., Du, Y., and Hu, Y. G. (2014). Genetic effects of dwarfing gene Rht-5 on agronomic traits in common wheat (Triticum aestivum L.) and QTL analysis on its linked traits. Field Crops Res. 156, 22-29. doi: 10.1016/j.fcr.2013.10.007

del Blanco, I. A., Rajaram, S., Kronstad, W. E., and Reynolds, M. P. (2000). Physiological performance of synthetic hexaploid wheat-derived populations. Crop Sci. 40, 1257-1263. doi: 10.2135/cropsci2000.4051257x 
De Vita, P., Li Destri Nicosia, O., Nigro, F., Platani, C., Riefolo, C., Di Fonzo, N., et al (2007). Breeding progress in morpho-physiological, agronomical and qualitative traits of durum wheat cultivars released in Italy during the 20th century. Eur. J. Agron. 26, 39-53. doi: 10.1016/j.eja.2006.08.009

Divashuk, M. G., Bespalova, L. A., and Vasilyev, A. V. (2013). Reduced height genes and their importance in winter wheat cultivars grown in southern Russia. Euphytica 190, 137. doi: 10.1007/s10681-012-0789-7

Dreccer, M. F., van Herwaarden, A. F., and Chapman, S. C. (2009). Grain number and grainweight in wheat lines contrasting for stem water soluble carbohydrate concentration. Field Crops Res. 112, 43-54. doi: 10.1016/j.fcr.2009.02.006

Du, Y., Chen, L., Wang, Y., Yang, Z., Saeed, I., Daoura, B. D., et al (2018). The combination of dwarfing genes Rht 4 and Rht 8 reduced plant height, improved yield traits of rainfed bread wheat (Triticum aestivum L.). Field Crops Res. 215, 149-155. doi: 10.1016/j.fcr.2017.10.015

Duggan, B. L., Richards, R. A., van Herwaarden, A. F., and Fettell, N. A. (2005). Agronomic evaluation of a tiller inhibition gene (tin) in wheat. effect yield yield components Grain protein. Aust. J. Agric. Res. 56, 169-178. doi: 10.1071/ AR04152

Ehdaie, B., Mohammadi, S. A., and Nouraein, M. (2016). QTLs for root traits at mid-tillering and for root and shoot traits at maturity in a RIL population of spring bread wheat grown under well-watered conditions. Euphytica 211, 17-38. doi: 10.1007/s10681-016-1670-x

Ellis, M. H., Rebetzke, G. J., Azanza, F., Richards, R. A., and Spielmeyer, W. (2005). Molecular mapping of gibberellin-responsive dwarfing genes in bread wheat. Theor. Appl. Genet. 111, 423-430. doi: 10.1007/s00122-005-2008-6

Fan, X., Cui, F., Zhao, C. H., Zhang, W., Yang, L., Zhao, X., et al (2015). QTL for flag leaf size and their influence on yield-related traits in wheat (Triticum aestivum L.). Mol. Breed. 35, 1-16. doi: 10.1007/s11032-015-0205-9

FAOSTAT. (2018). http:www.fao.org/faostat/en/\#data/QC. (Accessed 10 September 2018).

Ferrante, A., Savin, R., and Slafer, G. A. (2012). Differences in yield physiology between modern, well adapted durum wheat cultivars grown under contrasting conditions. Field Crops Res. 136, 52-64. doi: 10.1016/j.fcr.2012.07.015

Fischer, R. A., Rees, D., Sayre, K. D., Condon, G. A., and Larque, S. (1998). Wheat yield progress associated with higher stomatal conductance and photosynthetic rate and cooler canopies. Crop Sci. 38, 1467-1475. doi: 10.2135/cropsci1998.0 011183X003800060011x

Flohr, B. M., Hunt, J. R., Kirkegaard, J. A., Evans, J. R., Swan, A., and Rheinheimer, B. (2018). Genetic gains in NSW wheat cultivars from 1901 to 2014 as revealed from synchronous flowering during the optimum period. Eur. J. Agron. 98, 1-13. doi: 10.1016/j.eja.2018.03.009

Foulkes, M. J., Sylvester-Bradley, R., Weightman, R., and Snape, J. W. (2007). Identifying physiological traits associated with improved drought resistance in winter wheat. Field Crops Res. 103, 11-24. doi: 10.1016/j.fcr.2007.04.007

Fufa, H., Baenziger, P. S., Beecher, B. S., Graybosch, R. A., Eskridge, K. M., and Nelson, L. A. (2005). Genetic improvement trends in agronomic performances and end-use quality characteristics among hard winter wheat cultivars in Nebraska. Euphytica 144, 187-198. doi: 10.1007/s10681-005-5811-x

Gahlaut, V., Jaiswal, V., Tyagi, B. S., Singh, G., Sareen, S., and Balyan, H. S. (2017). QTL mapping for nine drought-responsive agronomic traits in bread wheat under irrigated and rain-fed environments. PloS One 12, e0182857. doi: 10.1371/journal.pone.0182857

Gaju, O., Reynolds, M. P., Sparkes, D. L., and Foulkes, M. J. (2009). Relationships between large-spike phenotype, grain number, and yield potential in spring wheat. Crop Sci. 49, 961-973. doi: 10.2135/cropsci2008.05.0285

Gaju, O., DeSilva, J., Carvalho, P., Hawkesford, M. J., Griffiths, S., Greenland, A., et al (2016). Leaf photosynthesis and associations with grain yield, biomass and nitrogen-use efficiency in landraces, synthetic-derived lines and cultivars in wheat. Field Crops Res. 193, 1-15. doi: 10.1016/j.fcr.2016.04.018

Gaju, O., Allard, V., Martre, P., Le Gouis, J., Moreau, D., Bogard, M., et al (2014). Nitrogen partitioning and remobilization in relation to leaf senescence, grain yield and grain nitrogen concentration in wheat cultivars. Field Crops Res. 155, 213-223. doi: 10.1016/j.fcr.2013.09.003

Gao, F., Wen, W., Liu, J., Rasheed, A., Yin, G., Xia, X., et al (2015). Genome-wide linkage mapping of QTL for yield components, plant height and yield-related physiological traits in the Chinese wheat. Front. Plant Sci. 6, 1099. doi: 10.3389/ fpls.2015.01099
Gao, F., Ma, D., Yin, G., Rasheed, A., Dong, Y., Xiao, Y., et al (2017). Genetic progress in grain yield and physiological traits in Chinese wheat cultivars of southern Yellow and Huai Valley since 1950. Crop Sci. 57, 760-773. doi: 10.2135/cropsci2016.05.0362

Gororo, N. N., Eagles, H. A., Eastwood, R. F., Nicolas, M. E., and Flood, R. G. (2002). Use of Triticum tauschii to improve yield of wheat in low-yielding environments. Euphytica 123, 241-254. doi: 10.1023/A:1014910000128

Gomez, D., Vanzetti, L., Helguera, M., Lombardo, L., Fraschina, J., and Miralles, D. J. (2014). Effect of Vrn-1, Ppd-1 genes and earliness per se on heading time in Argentinean bread wheat cultivars. Field Crops Res. 158, 73-81. doi: 10.1016/j.fcr.2013.12.023

Graybosch, R. A., and Peterson, C. J. (2010). Genetic improvement in winter wheat yieldsin the great plains of North America 1959-2008. Crop Sci. 50, 1882-1890. doi: 10.2135/cropsci2009.11.0685

Green, A. J., Berger, G., Griffey, C. A., Pitman, R., Thomason, W., and Balota, M. (2012). Genetic yield improvement in soft red winter wheat in theEastern United States from 1919 to 2009. Crop Sci. 52, 2097-2108. doi: 10.2135/ cropsci2012.01.0026

Grover, G., Sharma, A., Gill, H. S., Srivastava, P., and Bains, N. S. (2018). Rht8 gene as an alternate dwarfing gene in elite Indian spring wheat cultivars. PloS One. 13, e0199330. doi: 10.1371/journal.pone.0199330

Gummadov, N., Keser, M., Akin, B., Cakmak, M., Mert, Z., Taner, S., et al (2015) Genetic gains in wheat in Turkey: winter wheat for irrigated conditions. Crop J. 3, 507-516. doi: 10.1016/j.cj.2015.07.007

Giunta, F., Motzo, R., and Pruneddu, G. (2007). Trends since 1900 in the yield potential of Italian-bred durum wheat cultivars. Eur. J. Agron. 27, 12-24. doi: 10.1016/j.eja.2007.01.009

Guzmán, C., Autrique, E., Mondal, S., Huerta-Espino, J., Singh, R. P., Vargas, M., et al. (2017). Genetic improvement of grain quality traits for CIMMYT semidwarf spring bread wheat varieties developed during 1965-2015: 50 years of breeding. Field Crops Res. 210, 192-196. doi: 10.1016/j.fcr.2017.06.002

Hai, L., Guo, H., Wagner, C., Xiao, S., and Friedt, W. (2008). Genomic regions for yield and yield parameters in Chinese winter wheat (Triticum aestivum L.) genotypes tested under varying environments correspond to QTL in widely different wheat materials. Plant Sci. 175, 226-232. doi: 10.1016/j. plantsci.2008.03.006

Hamada, A., Nitta, M., Nasuda, S., Kato, K., Fujita, M., Matsunaka, H., et al (2012). Novel QTLs for growth angle of seminal roots in wheat (Triticum aestivum L.). Plant Soil. 354, 395-405. doi: 10.1007/s11104-011-1075-5

Hernández-Espinosa, N., Mondal, S., Autrique, E., Gonzalez-Santoyo, H., Cross, J., Huerta-Espino, J., et al (2018). Milling, processing and end-use quality traits of CIMMYT spring bread wheat germplasm under drought and heat stress. Field Crops Res. 215, 104-112. doi: 10.1016/j.fcr.2017.10.003

Houshmandfar, A., Rebetzke, G. J., Lawes, R., and Tausz, M. (2019). Grain yield responsiveness to water supply in near-isogenic reduced-tillering wheat lines - An engineered crop trait near its upper limit. Eur. J. Agron. 102, 33-38. doi: 10.1016/j.eja.2018.11.003

Hou, J., Huang, X., Sun, W., Du, C., Wang, C., Xie, Y., et al (2018). Accumulation of water-soluble carbohydrates and gene expression in wheat stems correlates with drought resistance. J. Plant Physiol. 231, 182-191. doi: 10.1016/j. jplph.2018.09.017

Huang, X., Coster, Q., Ganal, M. W., and Roder, M. S. (2003). Advanced backcross QTL analysis for the identification of quantitative trait loci alleles from wild relatives of wheat (Triticum aestivum L.). Theor. Appl. Genet. 106, 1379-1389. doi: 10.1007/s00122-002-1179-7

Ilyas, M., Ilyas, N., Arshad, M., Kazi, A. G., Kazi, A. M., and Waheed, A. (2014) QTL mapping of wheat doubled haploids for chlorophyll content and chlorophyll fluorescence kinetics under drought stress imposed at anthesis stage. Pak. J. Bot. 46, 1889-1897.

Joudi, M., Ahmadi, A., and Mohammadi, V. (2014). Genetic changes in agronomic and phenologic traits of Iranian wheat cultivars grown in different environmental conditions. Euphytica 196, 237-249. doi: 10.1007/ s10681-013-1027-7

Kabir, M. R., Liu, G., Guan, P., Wang, F., Khan, A. A., Ni, Z., et al (2015). Mapping QTLs associated with root traits using two different populations in wheat (Triticum aestivum L.). Euphytica 206, 175-190. doi: 10.1007/ s10681-015-1495-z 
Kamran, A., Randhawa, H. S., Pozniak, C., and Spaner, D. (2013a). Phenotypic Effects of the Flowering Gene Complex in Canadian Spring Wheat Germplasm. Crop Sci. 53, 84-94. doi: 10.2135/cropsci2012.05.0313

Kamran, A., Iqbal, M., and Navabi, A. (2013b). Earliness per se QTLs and their interaction with the photoperiod insensitive allele Ppd D1a in the Cutler $\times$ AC Barrie spring wheat population. Theor. Appl. Genet. 126, 1965. doi: 10.1007/ s00122-013-2110-0

Keser, M., Gummadov, N., Akin, B., Belen, S., Mert, Z., Taner, S., et al (2017). Genetic gains in wheat in Turkey: Winter wheat for dryland conditions. Crop J. 5, 533-540. doi: 10.1016/j.cj.2017.04.004

Kitonyo, M. O., Sadras, V. O., Zhou, Y., and Denton, M. D. (2017). Evaluation of historic Australian wheat varieties reveals increased grain yield and changes in senescence patterns but limited adaptation to tillage systems. Field Crops Res. 206, 65-73. doi: 10.1016/j.fcr.2017.02.017

Langer, S. M., Longin, C. F. H., and Würschum, T. (2014). Flowering time control in European winter wheat. Front. Plant Sci. 5, 537. doi: 10.3389/fpls.2014.00537

Lanning, S., Martin, J., Stougaard, R., Guillen-Portal, F., Blake, N., and Sherman, J. (2012). Evaluation of near-isogenic lines for three height-reducing genes in hard red spring wheat. Crop Sci. 52, 1145-1152. doi: 10.2135/cropsci2011.11.0625

Li, F., Wen, W., He, Z., Liu, J., Jin, H., Cao, S., et al. (2018). Genome-wide linkage mapping of yield-related traits in three Chinese bread wheat populations using high-density SNP markers. Theor. Appl. Genet. 131, 1903-1924. doi: 10.1007/ s00122-018-3122-6

Liu, H., Searle, I. R., Mather, D. E., Able, A. J., and Able, J. A. (2015). Morphological, physiological and yield responses of durum wheat to pre-anthesis water-deficit stress are genotype-dependent. Crop Past. Sci. 66, 1024-1038. doi: 10.1071/ CP15013

Liu, Y., Zhang, J., Hu, Y. G., and Chen, J. (2017). Dwarfing genes Rht4 and Rht-B1b affect plant height and key agronomic traits in common wheat under two water regimes. Field Crops Res. 204, 242-248. doi: 10.1016/j.fcr.2017.01.020

Liu, K., Xu, H., and Liu, G. (2018a). QTL mapping of flag leaf-related traits in wheat (Triticum aestivum L.). Theor. Appl. Genet. 131, 839. doi: 10.1007/ s00122-017-3040-Z

Liu, Y., Tao, Y., Wang, Z., Guo, Q., Wu, F., Yang, X., et al. (2018b). Identification of QTL for flag leaf length in common wheat and their pleiotropic effects. Mol. Breed. 38, 11. doi: 10.1007/s11032-017-0766-x

Liu, D., Zhang, L., Hao, M., Ning, S., Yuan, Z., Dai, S., et al. (2018c). Wheat breeding in the hometown of Chinese Spring. Crop J. 6, 82-90. doi: 10.1016/j. cj.2017.08.009

Lo Valvo, P. J., Mirallesa, D. J., and Serragoa, R. A. (2018). Genetic progress in Argentine bread wheat varieties released between 1918 and 2011: Changes in physiological and numerical yield components. Field Crops Res. 221, 314-321. doi: 10.1016/j.fcr.2017.08.014

Lopes, M. S., and Reynolds, M. P. (2010). Partitioning of assimilates to deeper roots is associated with cooler canopies and increased yield under drought in wheat. Funct. Plant Biol. 37, 147-156. doi: 10.1071/FP09121

Lopes, M. S., and Reynolds, M. P. (2012). Stay-green in spring wheat can be determined by spectral reflectance measurements (normalized difference vegetation index) independently from phenology. J. Exp. Bot. 63, 3789-3798. doi: $10.1093 /$ jxb/ers071

Lopes, M. S., Reynolds, M. P., Manes, Y., Singh, R. P., Crossa, J., and Braun, H. J. (2012). Genetic yield gains and changes in associated traits of CIMMYT spring bread wheat in a "historic" set representing 30 years of breeding. Crop Sci. 52, 1123-1131. doi: 10.2135/cropsci2011.09.0467

Lopes, M. S., Reynolds, M. P., and McIntyre, C. L. (2013). QTL for yield and associated traits in the Seri/Babax population grown across several environments in Mexico, in the West Asia, North Africa, and South Asia regions. Theor. Appl. Genet. 126, 971-984. doi: 10.1007/s00122-012-2030-4

Lozada, D. N., Mason, R. E., and Babar, M. A. (2017). Association mapping reveals loci associated with multiple traits that affect grain yield and adaptation in soft winter wheat. Euphytica 213, 222. doi: 10.1007/s10681-017-2005-2

Mackay, I. J., Horwell, A., Garner, J., White, J., McKee, J., and Philipott, H. (2011). Reanalyses of the historical series of UK variety trials to quantify the contributions of genetic and environmental factors to trends and variability in yield over time. Theor. Appl. Genet. 122, 225-238. doi: 10.1007/s00122-010-1438-y

Manès, Y., Gomez, H., Puhl, L., Reynolds, M., Braun, H., and Trethowan, R. (2012). Genetic yield gains of the CIMMYT international semi-arid wheat yield trials from 1994 to 2010. Crop Sci. 52, 1543-1552. doi: 10.2135/cropsci2011.10.0574
Mathew, I., Shimelis, H., Mwadzingeni, L., Zengeni, R., Mutema, M., and Chaplot, V. (2018). Variance components and heritability of traits related to root: shoot biomass allocation and drought tolerance in wheat. Euphytica. 214, 225. doi: 10.1007/s10681-018-2302-4

Matus, I., Mellado, M., Pinares, M., Madariaga, R., and del Pozo, A. (2012). Genetic progress in winter wheat cultivars released in Chile from 1920 to 2000 Chilean J. Agric. Res. 72, 303-308. doi: 10.4067/S0718-58392012000300001

Maqsood, R. M., Amjid, M. S., Saleem, M. A., Shabbir, G., and Khaliq, I. (2017). Identification of genomic regions conferring drought tolerance in bread wheat using ISSR markers. Pak. J. Bot. 49, 1821-1827.

McIntosh, R. A., Yamazaki, Y., Dubcovsky, J., Rogers, W. J., Morris, C., Appels, R., et al, (2013). "Catalogue of gene symbols for wheat," in In: Proceedings of 12th International wheat genetics Symposium(Yokohama, Japan). http://www.shigen. nig.ac.jp/wheat/.

Merchuk-Ovnat, L., Fahima, T., Krugman, T., and Saranga, Y. (2016). Ancestral QTL alleles from wild emmer wheat improve grain yield, biomass and photosynthesis across enviroinments in modern wheat. Plant Sci. 251, 23-34. doi: $10.1016 /$ j.plantsci.2016.05.003

Mitchell, J. H., Chapman, S. C., Rebetzke, G. J., Bonnett, D. G., and Fukai, S. (2012). Evaluation of a reduced-tillering (tin) gene in wheat lines grown across different production environments. Crop Past. Sci. 63, 128-141. doi: 10.1071/ CP11260

Mkhabela, S. S., Shimelis, H., Odindo, A. O., and Mashilo, J. (2019). Response of selected drought tolerant wheat (Triticum aestivum L.) genotypes for agronomic traits and biochemical markers under drought-stressed and nonstressed conditions. Acta Agric. Scand. Sect B - Soil Plant Sci. 69, 674-689. doi: 10.1080/09064710.2019.1641213

Mo, Y., Vanzetti, L. S., Hale, I., Spagnolo, E. J., Guidobaldi, F., Al-Oboudi, J., et al (2018). Identification and characterization of Rht25, a locus on chromosome arm 6AS affecting wheat plant height, heading time, and spike development. Theor. Appl. Genet. 131, 2021-2035. doi: 10.1007/s00122-018-3130-6

Moeller, C., Evers, J. B., and Rebetzke, G. (2014). Canopy architectural and physiological characterization of near-isogenic wheat lines differing in the tiller inhibition gene tin. Front. Plant Sci. 5, 617. doi: 10.3389/fpls.2014.00617

Mondal, S., Singh, R. P., Mason, E. R., Huerta-Espino, J., Autrique, E., and Joshi, A. K. (2016). Grain yield, adaptation and progress in breeding for early-maturing and heat-tolerant wheat lines in South Asia. Field Crops Res. 192, 78-85. doi: 10.1016/j.fcr.2016.04.017

Morgounov, A., Zykinb, V., Belanb, I., Roseevab, L., Zelenskiyc, Y., GomezBecerrad, H. F., et al (2010). Genetic gains for grain yield in high latitude spring wheat grown in Western Siberia in 1900-2008. Field Crops Res. 117, 101-112. doi: 10.1016/j.fcr.2010.02.001

Motzo, R., Giunta, F., and Deidda, M. (2004). Expression of a tiller inhibitor gene in the progenies of interspecific crosses Triticum aestivum L. $\times$ T. turgidum subsp durum. Field Crops Res. 85, 15-20. doi: 10.1016/S0378-4290(03)00123-0

Motzo, R., and Giunta, F. (2007). The effect of breeding on the phenology of Italian durum wheats: From and races to modern cultivars. Eur. J. Agron. 26, 462-470. doi: 10.1016/j.eja.2007.01.007

Naruoka, Y., Talbert, L. E., Lanning, S. P., Blake, N. K., Martin, J. M., and Sherman, J. D. (2011). Identification of quantitative trait loci for productive tiller number and its relationship to agronomic traits in spring wheat. Theor. Appl. Genet. 123, 1043-1053. doi: 10.1007/s00122-011-1646-0

Nhemachena, C. R., and Kirsten, J. (2017). A historical assessment of sources and uses of wheat varietal innovations in South Africa. SA. J. Sci. 113, 1-8. doi: 10.17159/sajs.2017/20160008

Nishimura, K., Moriyama, R., and Katsura, K. (2018). The early flowering trait of an emmer wheat accession (Triticum turgidum L. ssp. dicoccum) is associated with the cis-element of the Vrn-A3 locus. Theor. Appl. Genet. 131, 2037. doi: 10.1007/s00122-018-3131-5

Ochagavía, H., Prieto, P., Savin, R., Griffiths, S., and Slafer, G. (2018). Dynamics of leaf and spikelet primordia initiation in wheat as affected by Ppd-1a alleles under field conditions. J. Exp. Bot. 69, 2621-2631. doi: 10.1093/jxb/ery104

Ogbonnaya, F. C., Rasheed, A., Okechukwu, E. C., Jighly, A., Makdis, F., Wuletaw, T., et al. (2017). Genome wide association study for agronomic and physiological traits in spring wheat evaluated in a range of heat prone environments. Theor. Appl. Genet. 130, 1819. doi: 10.1007/s00122-017-2927-z

Ortiz, R., Braun, H., Crossa, J., Crouch, J. H., Davenport, G., Dixon, J., et al. (2008), Wheat genetic resources enhancement by the International Maize and Wheat 
Improvement Center (CIMMYT). Genet. Resour. Crop Evol. 55, 1095-1140. doi: $10.1007 /$ s10722-008-9372-4

Oury, F. X., Godin, C., Mailliard, A., Chassin, A., Gardet, O., Giraud, A., et al (2012). A study of genetic progress due to selection reveals a negative effect of climate change on bread wheat yield in France. Eur. J. Agron. 40, 28-38. doi: 10.1016/j.eja.2012.02.007

Parry, M. A. J., Reynolds, M., Salvucci, M. E., Raines, C., Andralojc, P. J., and Zhu, X. G. (2011). Raising yield potential of wheat. II. Increasing photosynthetic capacity and efficiency. J. Exp. Bot. 62, 45-467. doi: 10.1093/jxb/erq304

Pask, A. J. D., and Reynolds, M. P. (2013). Breeding for yield potential has increased deep water extraction capacity in irrigated wheat. Crop Sci. 53, 1-15. doi: 10.2135/cropsci2013.01.0011

Perez-Lara, E., Semagn, K., Chen, H., Iqbal, M., N'Diaye, A., Kamran, A., et al (2016). QTLs associated with agronomic traits in the Cutler $\times$ AC Barrie spring wheat mapping population using Single Nucleotide Polymorphic Markers. PloS One 11, 1-19. doi: 10.1371/journal.pone.0160623

Pinto, R. S., and M.P, Reynolds (2015). Common genetic basis for canopy temperature depression under heat and drought stress associated with optimized root distribution in bread wheat. Theor. Appl. Genet. 128, 575-585. doi: 10.1007/s00122-015-2453-9

Pinto, R. S., Molero, G., Reynolds, M. P., and Ibrahim, A. (2017). Identification of heat tolerant wheat lines showing genetic variation in leaf respiration and other physiological traits. Euphytica 213, 76. doi: 10.1007/s10681-017-1858-8

Qin, X., Zhang, F., Liu, C., Yu, H., Cao, B., Tian, S., et al. (2015). Wheat yield improvements in China: past trends and future directions. Field Crops Res. 177, 117-124. doi: 10.1016/j.fcr.2015.03.013

Rebetzke, G. J., Bruce, S., and Kirkegaard, J. A. (2005). Genotypic increases in coleoptile length improves emergence and early vigour with crop residues. Plant Soil 270, 87-100. doi: 10.1007/s11104-004-4040-8

Rebetzke, G. J., van Herwaarden, A. F., Jenkins, C., Weiss, M., Lewis, D., Ruuska, S., et al (2008). Quantitative trait loci for water-soluble carbohydrates and associations with agronomic traits in wheat. Aust. J. Agric. Res. 59, 891-905. doi: 10.1071/AR08067

Rebetzke, G. J., Ellis, M. H., Bonnett, D. G., Condon, A. G., Falk, D., and Richards, R. A. (2011). The Rht13 dwarfing gene reduces peduncle length and plant height to increase grain number and yield of wheat. Field Crops Res. 124, 323331. doi: 10.1016/j.fcr.2011.06.022

Rebetzke, G. J., Ellis, M. H., Bonnett, D. G., Mickelson, B., Condon, A. G., and Richards, R. A. (2012a). Height reduction and agronomic performance for selected gibberellin-responsive dwarfing genes in bread wheat (Triticum aestivum L.). Field Crops Res. 126, 87-96. doi: 10.1016/j.fcr.2011.09.022

Rebetzke, G. J., Bonnett, D. G., and Ellis, M. H. (2012b). Combining gibberellic acid-sensitive and insensitive dwarfing genes in breeding of higher-yielding, sesqui-dwarf wheats. Field Crops Res. 127, 17-25. doi: 10.1016/j.fcr.2011.11.003

Rebetzke, G. J., Biddulph, B., Chenu, K., Deery, D., Mayer, J., and Moeller, C. (2013). Development of a multisite, managed environment facility for targeted trait and germplasm evaluation. Funct. Plant Biol. 40, 1-13. doi: 10.1071/ FP12180

Ren, Y., Li, J., He, X., Zhao, X., Li, B., and Tong, Y. (2010). Fine mapping a major QTL for root morphology in wheat. J. Biotechnol. 150, 113-114. doi: 10.1016/j. jbiotec.2010.08.293

Ren, Y., He, X., Liu, D., et al (2012). Major quantitative trait loci for seminal root morphology of wheat seedlings. Mol. Breed. 30, 139-148. doi: 10.1007/ s11032-011-9605-7

Reynolds, M., and Tuberosa, R. (2008). Translational research impacting on crop productivity in drought-prone environments. Curr. Opin. Plant Biol. 11, 171179. doi: 10.1016/j.pbi.2008.02.005

Reynolds, M., Foulkes, J., Furbank, R., Griffiths, S., King, J., Murchie, E., et al (2012). Achieving yield gains in wheat. Plant Cell Environ. 35, 1799-1823. doi: 10.1111/j.1365-3040.2012.02588.x

Reynolds, M., Tattaris, M., Cossani, C. M., Ellis, M., Yamaguchi-Shinozaki, K., and Pierre, C. S., (2015). "Exploring genetic resources to increase adaptation of wheat to climate change," in Advances in Wheat Genetics: From Genome to Field. Eds. Ogihara, Y., Takumi, S., and Handa, H. (Tokyo: Springer). doi: 10.1007/978-4-431-55675-6_41

Reynolds, M. P., Pask, A. J. D., Hoppitt, W. J. E., Sonder, K., Sukumaran, S., Molero, G., et al. (2017). Strategic crossing of biomass and harvest index-source and sink-achieves genetic gains in wheat Euphytica 213, 257. doi: 10.1007/ s10681-017-2040-z

Rosegrant, M. W., and Agcaoili, M., (2010). Global food demand, supply, and price prospects to 2010. Washington, DC: International Food Policy Research Institute.

Royo, C., Álvaro, F., Martos, V., Ramdani, A., Isidro, J., Villegas, D., et al (2007). Genetic changes in durum wheat yield components and associated traits in Italian and Spanish varieties during the 20th century. Euphytica 155, 259-270. doi: 10.1007/s10681-006-9327-9

Royo, C., Ammar, K., Alfaro, C., Dreisigacker, S., García del Moral, L. F., and Villegas, D. (2018). Effect of Ppd-1 photoperiod sensitivity genes on dry matter production and allocation in durum wheat. Field Crops Res. 221, 358-367. doi: 10.1016/j.fcr.2017.06.005

Ruuska, S. A., Rebetzke, G. J., van Herwaarden, A. F., Richards, R. A., Fettell, N. A., Tabe, L., et al (2006). Genotypic variation in water-soluble carbohydrate accumulation in wheat. Funct. Plant Biol. 33, 799-809. doi: 10.1071/FP06062

Sadras, V. O., and Lawson, C. (2011). Genetic gain in yield and associated changes in phenotype, trait plasticity and competitive ability of South Australian wheat varieties released between 1958 and 2007. Crop Past. Sci. 62, 533-549. doi: 10.1071/CP11060

Sadras, V. O., and Rebetzke, G. J. (2013). Plasticity of wheat grain yield is associated with plasticity of ear number. Crop Past. Sci. 64, 234-243. doi: 10.1071/CP13117

Sadras, V. O., and Lawson, C. (2013). Nitrogen and water-use efficiency of Australian wheat varieties released between 1958 and 2007. Eur. J. Agron. 46, 34-41. doi: 10.1016/j.eja.2012.11.008

Sayre, K. D., Rajaram, S., and Fischer,R. A. (1997). Yield potential progress in short wheats in northwest Mexico. Crop Sci. 37, 36-42. doi: 10.2135/cropsci1997.00 11183X003700010006x

Sharma, R. C., Crossa, J., Velu, G., Huerta-Espino, J., Vargas, M., Payne, T. S., et al (2012). Genetic gains for grain yield in CIMMYT spring bread wheat across international environments. Crop Sci. 52, 1522-1533. doi: 10.2135/ cropsci2011.12.0634

Shearman, V. J., Sylvester-Bradley, R., Scott, R. K., and Foulkes, M. J. (2005). Physiological processes associated with wheat yield progress in the UK. Crop Sci. 45, 175-185. doi: 10.2135/cropsci2005.0175

Soriano, J. M., and Alvaro, F. (2019). Discovering consensus genomic regions in wheat for root-related traits by QTL meta-analysis. Sci. Rep. 9, 10537. doi: 10.1038/s41598-019-47038-2

Sukumaran, S., Lopes, M., and Dreisigacker, S. (2018). Genetic analysis of multienvironmental spring wheat trials identifies genomic regions for locus-specific trade-offs for grain weight and grain number. Theor. Appl. Genet. 131, 985. doi: $10.1007 / \mathrm{s} 00122-017-3037-7$

Sun, Y., Wang, X., Wang, N., Chen, Y., and Zhang, S. (2014). Changes in the yield and associated photosynthetic traits of dry-land winter wheat (Triticum aestivum L.) from the 1940 to the 2010 in Shanxi Province of China. Field Crops Res. 167, 1-10. doi: 10.1016/j.fcr.2014.07.002

Tahmasebi, S., Heidari, B., Pakniyat, H., and McIntyre, C. L. (2016). Mapping QTLs associated with agronomic and physiological traits under terminal drought and heat stress conditions in wheat (Triticum aestivum L.). Genome 59, 1-20. doi: 10.1139/gen-2016-0017

Tausz-Posch, S., Dempsey, R. W., Seneweera, S., Norton, R. M., Fitzgerald, G., and Tausz, M. (2015). Does a freely tillering wheat cultivar benefit more from elevated $\mathrm{CO} 2$ than a restricted tillering cultivar in a water-limited environment? Eur. J. Agron. 64, 21-28. doi: 10.1016/j.eja.2014.12.009

Telfer, P., Edwards, J., Bennett, D., Ganesalingam, D., Able, J., and Kuchel, H. (2018). A field and controlled environment evaluation of wheat (Triticum aestivum) adaptation to heat stress. Field Crops Res. 229, 55-65. doi: 10.1016/j. fcr.2018.09.013

Thapa, S., Jessup, K. E., Pradhan, G. P., Rudd, J. C., Liu, S., Mahan, J. R., et al (2018). Canopy temperature depression at grain filling correlates to winter wheat yield in the U.S. South. High Plains. Field Crops Res. 217, 11-19. doi: 10.1016/j. fcr.2017.12.005

Tian, Z., Jing, Q., Dai, T., Jiang, D., and Cao, W. (2011). Effects of genetic improvements on grain yield and agronomic traits of winter wheat in the Yangtze River Basin of China. Field Crops Res. 124, 417-425. doi: 10.1016/j. fcr.2011.07.012 
Tian, X., Zhu, Z., Xie, L., Xu, D., Li, J., Fu, C., et al. (2019). Preliminary exploration of the source, spread, and distribution of Rht 24 reducing height in bread wheat. Crop Sci. 59, 19-24. doi: 10.2135/cropsci2017.12.0711

Vikhe, P., Venkatesan, S., Chavan, A., Tamhankar, S., and Patil, R. (2018). Mapping of dwarfing gene Rht14 in durum wheat and its effect on seedling vigor, internode length and plant height. Crop J. 7, 187-197. doi: 10.1016/j.cj.2018.11.004

Underdahl, J. L., Mergoum, M., Ransom, J. K., and Schatz, B. G. (2008). Agronomic traits improvement and associations in hard red spring wheat cultivars released in North Dakota from 1968 to 2006. Crop Sci. 48, 158-166. doi: 10.2135/ cropsci2007.01.0018

van Beem, J., Mohler, V., Lukman, R., van Ginkel, M., William, M., Crossa, J., et al (2005). Analysis of genetic factors influencing the developmental rate of globally important CIMMYT wheat cultivars. Crop Sci. 45, 2113-2119. doi: 10.2135/cropsci2004.0665

Wang, Y., Chen, L., Du, Y., Yang, Z., Condon, A. G., and Hu, Y. G. (2014). Genetic effect of dwarfing gene Rht13 compared with Rht-D1b on plant height and some agronomic traits in common wheat (Triticum aestivum L.). Field Crops Res. 162, 39-47. doi: 10.1016/j.fcr.2014.03.014

Wang, Y., Du, Y., Yang, Z., Chen, L., Condon, A. G., and Hu, Y. G. (2015). Comparing the effects of GA-responsive dwarfing genes Rht13 and Rht8 on plant height and some agronomic traits in common wheat. Field Crops Res. 179, 35-43. doi: 10.1016/j.fcr.2015.04.010

Wang, Z., Liu, Y., and Shi, H. (2016). Identification and validation of novel lowtiller number QTL in common wheat. Theor. Appl. Genet. 129, 603-612. doi: 10.1007/s00122-015-2652-4

Wang, R., Liu, Y., and Isham, K. (2018). QTL identification and KASP marker development for productive tiller and fertile spikelet numbers in two highyielding hard white spring wheat cultivars. Mol. Breed. 38, 135. doi: 10.1007/ s11032-018-0894-y

Wu, X., Chang, X., and Jing, R. (2012). Genetic insight into yield-associated traits of wheat grown in multiple rain-fed environments. PloS One 7, e31249. doi: 10.1371/journal.pone.0031249

Wu, W., Li, C., and Ma, B. (2014). Genetic progress in wheat yield and associated traits in China since 1945 and future prospects. Euphytica 196, 155-168. doi: 10.1007/s10681-013-1033-9

Wu, Q., Chen, Y., and Fu, L. (2016). QTL mapping of flag leaf traits in common wheat using an integrated high-density SSR and SNP genetic linkage map. Euphytica 208, 337-351. doi: 10.1007/s10681-015-1603-0

Würschum, T., Langer, S. M., and Longin, C. F. H. (2015). Genetic control of plant height in European winter wheat cultivars. Theor. Appl. Genet. 128, 865-874. doi: 10.1007/s00122-015-2476-2

Würschum, T., Langer, S. M., Longin, C. F. H., Tucker, M. R., and Leiser, W. L. (2017). A modern Green Revolution gene for reduced height in wheat. Plant J. 92, 892-903. doi: 10.1111/tpj.13726

Würschum, T., Leiser, W. L., and Langer, S. M. (2018). Phenotypic and genetic analysis of spike and kernel characteristics in wheat reveals long-term genetic trends of grain yield components. Theor. Appl. Genet. 131, 2071-2084. doi: 10.1007/s00122-018-3133-3

Xiao, Y. G., Qian, Z., G., K., Liu, J. J., Xia, X. C., Ji, W. Q., et al (2012). genetic gains in grain yield and physiological traits of winter wheat in Shandong Province, China, from 1969 to 2006. Crop Sci. 52, 44-56. doi: 10.2135/ cropsci2011.05.0246

Xie, W., and Nevo, E. (2008). Wild emmer: Genetic resources, gene mapping and potential for wheat improvement. Euphytica. 164, 603-614. doi: 10.1007/ s10681-008-9703-8

Xu, Y., Li, S., and Li, L. (2017). QTL mapping for yield and photosynthetic related traits under different water regimes in wheat. Mol. Breed. 37, 34. doi: 10.1007/ s11032-016-0583-7

Yang, D., Jing, R., Chang, X., and Li, W. (2007a). Quantitative trait loci mapping for chlorophyll fluorescence and associated traits in wheat (Triticum aestivum). J. Integr. Plant Biol. 49, 646-654. doi: 10.1111/j.1744-7909.2007.00443.x
Yang, D., Jing, R., Chang, X., and Li, W. (2007b). Identification of quantitative trait loci and environmental interactions for accumulation and remobilization of water-soluble carbohydrates in wheat (Triticum aestivum L.) stems. Genetics 176, 571-584. doi: 10.1534/genetics.106.068361

Yang, Z., Zheng, J., Liu, C., Wang, Y., Condon, A. G., Chen, Y., et al (2015) Effects of the GA-responsive dwarfing gene Rht18 from tetraploid wheat on agronomic traits of common wheat. Field Crops Res. 183, 92-101. doi: 10.1016/j.fcr.2015.07.028

Yu, M., Mao, S., and Chen, G. (2014). QTLs for uppermost internode and spike length in two wheat RIL populations and their affect upon plant height at an individual QTL level. Euphytica 200, 95-108. doi: 10.1007/s10681-014-1156-7

Zhang, X., Yang, S., and Zhou, Y. (2006). Distribution of the Rht-B1b, Rht-D1b and Rht8 reduced height genes in autumn-sown Chinese wheats detected by molecular markers. Euphytica 152, 109-116. doi: 10.1007/s10681-006-9184-6

Zhang, X. K., Xiao, Y. G., Zhang, Y., Xia, X. C., Dubcovsky, J., and He, Z. H. (2008). allelic variation at the vernalization genes Vrn-A1, Vrn-B1, Vrn-D1, and VrnB3 in Chinese wheat cultivars and their association with growth habit. Crop Sci. 48, 458-470. doi: 10.2135/cropsci2007.06.0355

Zhang, K., Zhang, Y., Chen, G., and Tian, J. (2009). Genetic analysis of grain yield and leafChlorophyll content in common wheat. Cereal Res. Commun. 37, 499511. doi: 10.1556/CRC.37.2009.4.3

Zhang, Y., Xu, W., Wang, W., Dong, H., Qi, X., Zhao, M., et al (2016). Progress in genetic improvement of grain yield and related physiological traits of Chinese wheat in Henan Province. Field Crops Res. 199, 117-128. doi: 10.1016/j. fcr.2016.09.022

Zhang, Y., Li, D., Zhang, D., Zhao, X., Cao, X., Dong, L., et al (2018). Analysis of the functions of TaGW2 homoeologs in wheat grain weight and protein content traits. Plant J. 94, 857-866. doi: 10.1111/tpj.13903

Zhang, Z., Wang, P., Li, Y., Ma, L., Li, L., Yang, R., et al (2014). Global transcriptome analysis and identification of the flowering regulatory genes expressed in leaves of Lagerstroemia indica. DNA Cell Biol. 33, 680-688. doi: 10.1089/ dna.2014.2469

Zhao, C., Bao, Y., and Wang, X. (2018). QTL for flag leaf size and their influence on yield-related traits in wheat. Euphytica 214, 209. doi: 10.1007/ s10681-018-2288-y

Zheng, T. C., Zhang, X. K., Yina, G. H., Wanga, L. N., Hana, Y. L., Chen, L., et al (2011). Genetic gains in grain yield, net photosynthesisand stomatal conductance achieved in Henan Province of China between 1981and 2008. Field Crops Res. 122, 225-233. doi: 10.1016/j.fcr.2011.03.015

Zheng, B., Biddulph, B., Li, D., Kuchel, H., and Chapman, S. (2013). Quantification of the effects of VRN1 and Ppd-D1 to predict spring wheat (Triticum aestivum) heading time across diverse environments. J. Exp. Bot. 64, 3747-3761. doi: 10.1093/jxb/ert209

Zhou, Y., Zhu, H. Z., and Cai, S. B. (2007a). Genetic improvement of grain yield and associated traits in the southern China winter wheat region: 1949 to 2000. Euphytica 157, 465-473. doi: 10.1007/s10681-007-9376-8

Zhou, Y., He, Z., Sui, X., Xia, X., Zhang, X., and Zhang, G. (2007b). Genetic improvement of grain yield and associated traits in the Northern China winter wheat region from 1960 to 2000. Crop Sci. 47, 245-253. doi: 10.2135/ cropsci2006.03.0175

Conflict of Interest: The authors declare that the research was conducted in the absence of any commercial or financial relationships that could be construed as a potential conflict of interest.

Copyright (C) 2019 Tshikunde, Mashilo, Shimelis and Odindo. This is an open-access article distributed under the terms of the Creative Commons Attribution License (CC $B Y)$. The use, distribution or reproduction in other forums is permitted, provided the original author(s) and the copyright owner(s) are credited and that the original publication in this journal is cited, in accordance with accepted academic practice. No use, distribution or reproduction is permitted which does not comply with these terms. 